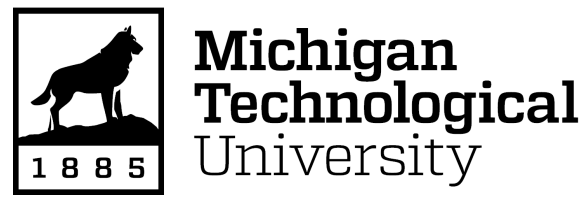

Michigan Technological University Digital Commons @ Michigan Tech

Dissertations, Master's Theses and Master's Reports

2017

\title{
Multi-Modal and Short-Range Transmission Loss in Ice-Covered, Near-Shore Arctic Waters
}

Miles B. Penhale

Michigan Technological University, mbpenhal@mtu.edu

Copyright 2017 Miles B. Penhale

\section{Recommended Citation}

Penhale, Miles B., "Multi-Modal and Short-Range Transmission Loss in Ice-Covered, Near-Shore Arctic Waters", Open Access Master's Report, Michigan Technological University, 2017.

https://doi.org/10.37099/mtu.dc.etdr/453

Follow this and additional works at: https://digitalcommons.mtu.edu/etdr

Part of the Acoustics, Dynamics, and Controls Commons, Ocean Engineering Commons, Oceanography Commons, and the Other Physical Sciences and Mathematics Commons 


\title{
MULTI-MODAL AND SHORT-RANGE TRANSMISSION LOSS IN ICE-COVERED, NEAR-SHORE ARCTIC WATERS
}

By

Miles B. Penhale

\begin{abstract}
A REPORT
Submitted in partial fulfillment of the requirements for the degree of MASTER OF SCIENCE

In Mechanical Engineering
\end{abstract}

MICHIGAN TECHNOLOGICAL UNIVERSITY

2017

(C) 2017 Miles B. Penhale 
This report has been approved in partial fulfillment of the requirements for the Degree of MASTER OF SCIENCE in Mechanical Engineering.

Department of Mechanical Engineering - Engineering Mechanics

Report Advisor: $\quad$ Andrew Barnard
Committee Member: $\quad$ Charles Van Karsen

Committee Member: Jason Blough

Committee Member: $\quad$ Roger Turpening

Department Chair: $\quad$ William W. Predebon 
Table of Contents

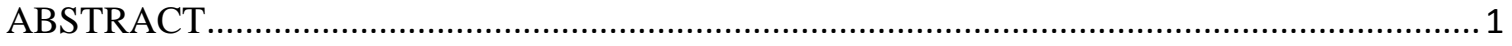

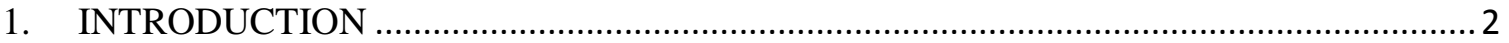

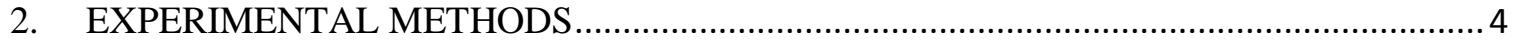

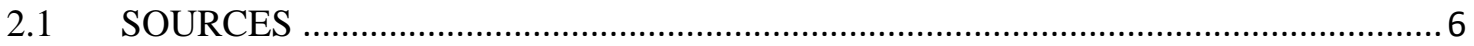

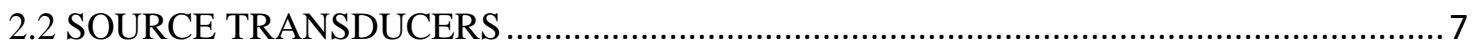

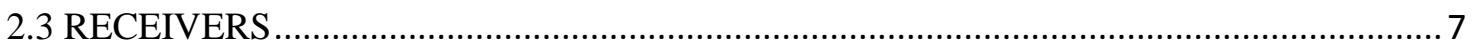

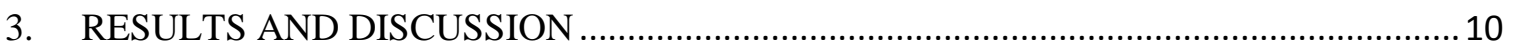

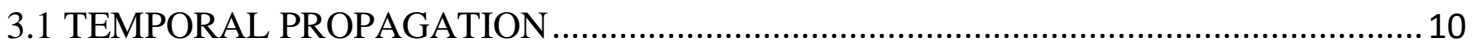

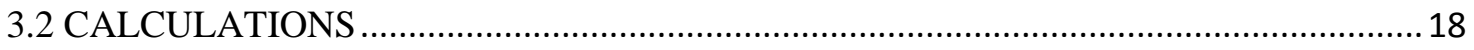

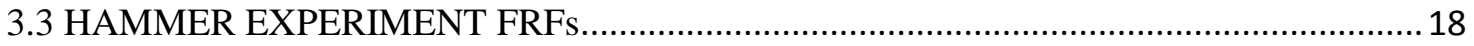

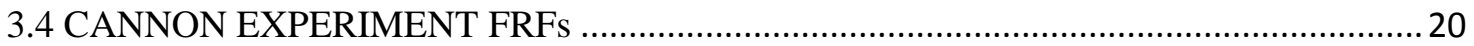

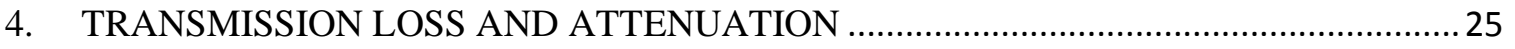

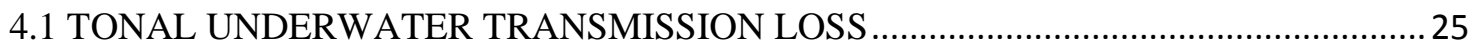

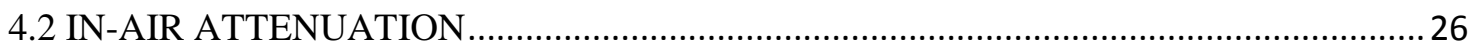

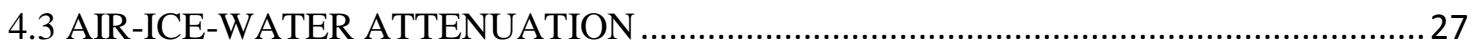

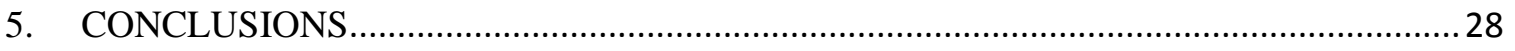

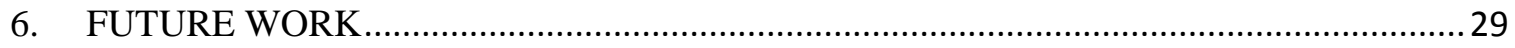

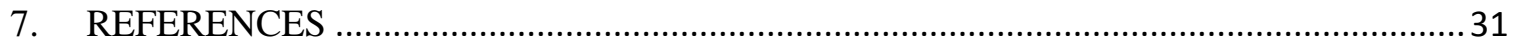





\section{ABSTRACT}

In the past century, extensive research has been done regarding the sound propagation in arctic ice sheets. The majority of this research has focused on low frequency propagation over long distances. One of the most commonly used excitation methods for air-icewater layers has been explosives. However, environmental regulation has become more stringent, disallowing the use of almost all explosive excitation types. Due to changing climate conditions in these environments, new experimentation is warranted to determine sound propagation characteristics in, through, and under thin ice sheets, in shallow water, over short distances. In April, 2016 several experiments were conducted approximately 2 $\mathrm{km}$ off the coast of Barrow, Alaska on shore-fast, first year ice, approximately $1 \mathrm{~m}$ thick. To determine the propagation characteristics of various sound sources, Frequency Response Functions (FRFs) were measured between a source location and several receiver locations at various distances from $1 \mathrm{~m}$ to $1 \mathrm{~km}$. The primary sources used for this experiment were, an underwater speaker with various tonal outputs, an instrumented impact-hammer on the ice, and a propane cannon that produced an acoustic blast wave in air. The transmission characteristics of the multipath propagation (air, ice, water) are investigated and reported. 


\section{INTRODUCTION}

In the past century, there has been a great deal of research conducted regarding seismoacoustic propagation in multilayered media such as air, ice, and water. In floating ice sheets, the theory of wave propagation is well developed [1-7] and has been corroborated by several experiments [8-15]. Typically, seismo-acoustic research in floating ice layers focuses on propagation time, phase velocity, and group velocity of various types of waves such as P-waves (compression wave), S-waves (transverse shear wave), Rayleigh waves (flexural surface wave), and Love waves (shear surface wave).

P-waves and S-waves are known to travel through the body of a solid and are often assumed to be non-dispersive in nature for media with low intrinsic absorption [16, 17]. For nondispersive waves, the propagation speed does not change with frequency. Surface waves, by comparison, are dispersive. In dispersive waves, the wave speed of any given frequency component is called its phase velocity. While the speed of the superposition of all frequencies is called the group velocity.

In typical seismo-acoustic studies in the earth, surface waves travel at higher speeds for lower frequencies [16]. A lower frequency surface wave will penetrate deeper into the earth than a higher frequency wave. Deeper layers in the earth are more dense and have properties which cause propagation speed to increase and therefore, lower frequency waves will travel faster. However, this generalization about dispersion cannot be made for layered arctic media such as floating ice sheets.

When the phase velocity of a flexural surface wave is very close to the speed of sound in air, an air-coupled flexural wave can also be observed. These have been observed in thin, floating ice sheets [3, 8]. Air coupled flexural waves happen because the compressional air wavefront imparts energy into the solid media as it travels. Therefore, there is a continual excitation of the flexural wave at the wavefront of the air wave. In general, there are two types of air-coupled flexural waves which have been observed in previous research: air-coupled Rayleigh waves and air-coupled gravity waves.

Air-coupled Rayleigh waves are similar to other types of elastic waves in that they have restorative forces due to their elastic properties. Air-coupled gravity waves, by comparison, are restored due to the gravitational force alone. Another main distinguishing feature between these waves has to do with their arrival with respect to a fixed position. For air-coupled gravity waves, the group velocity of the wave is faster than the speed of sound in air. Therefore, the air-coupled gravity wave will be observed before the pressure wave in air, but the flexural wave will immediately terminate when the pressure wave arrives. Conversely, the air-coupled Rayleigh wave does not start until the pressure wave arrives, indicating a group velocity which is slower than the sound speed in air. [3, 4, 7, 8]

By measuring the difference in wave arrival time at various sensor array locations, the wave speeds for various wave types (compressive, flexural, and shear) can be determined. From the wave propagation characteristics, the ice elastic properties can also be calculated in experimental studies. Elastic properties, or other environmental properties, are often 
assumed for modeling purposes, and propagation times and velocities are determined. Because the underlying theory of these waves is well developed, it will not be explored in depth in this paper.

With the exception of a few studies $[12,18]$, the majority of the previously mentioned research focuses on low frequency (approximately less than $100 \mathrm{~Hz}$ ) propagation over long-ranges (generally greater than $1 \mathrm{~km}$ ).

Early experiments often excited layered media with explosives. This excitation method is becoming much less common due to environmental regulation and restriction on explosive acoustic sources [19]. Due to these restrictions, unique excitation methods are becoming necessary. Some recent techniques for ice excitation include freezing a wooden or steel post into the ice and hitting the post with a sledgehammer [13, 20]. For underwater excitation, lightbulbs, or other crushable containers, have been placed at depth and imploded to create an acoustic source $[19,20]$. While some studies take care to control the source excitation levels in some manner [18, 20], the source levels have not been systematically quantified or measured.

It is well known that the global climate change is affecting the arctic ice layers [21-26]. In general, the ice layers are becoming much thinner than they were when early acoustic experiments were taking place. For example, multi-year ice is now melting between seasons. The current conditions support first-year, shore-fast ice which is more saline and of different density and strength than multi-year pack ice [27]. Therefore, old models which have been used to describe acoustic propagation in the arctic may no longer be valid. The primary aim of our research is to gather new experimental data for characterization of the transmission path in the near-shore arctic and to build new models of the thinning ice environment.

In addition, this changing arctic environment warrants new investigation into the acoustic detection, identification, and tracking of anthropogenic sources. Because there is less ice in the arctic environment for longer time periods during the year, there is expected to be more anthropogenic activity [24-26, 28-30]. It is of interest to determine the location and type of these anthropogenic sources. Since the ice layers are becoming more commonly shore-fast and in shallow water, the environment where sources must be sensed is becoming less understood and increasingly complex. It is a secondary aim of our research to use our new data to determine effective methods for detection, identification, and tracking of anthropogenic sources in shallow water with thin, irregular ice sheets.

Typically, acoustic propagation data has been measured by utilizing arrays of geophones on the ice surface, hydrophones underwater, or microphones in the air. Sometimes combinations of either geophones and hydrophones, or geophones and microphones have been used. However, the combination of all three sensor types is quite uncommon and is something that we will implement in hopes of aiding in source detection, identification, and tracking.

To our knowledge, no experiments have been conducted in arctic environments regarding the multimodal ice response to various sources when the source levels are quantified. In 
the industrial noise and vibration field, a common method for determining acoustic path characteristics is calculation of Frequency Response Functions (FRFs) [31-33]. This method has not been used in the seismo-acoustic or arctic-acoustic field to our knowledge. In this paper, we use FRFs to quantify the multipath characteristics in the arctic environment. Using FRF calculations we determine the frequency domain ratio of microphone, geophone, and hydrophone responses to various measured source inputs. Namely, these sources are all non-explosive in nature: a small propane cannon, instrumented impact hammer, and an underwater speaker.

\section{EXPERIMENTAL METHODS}

Acoustic propagation measurements were recorded during April 8-15, 2016. All measurements were conducted approximately $2 \mathrm{~km}$ from the coast of Barrow, Alaska on first-year, shore-fast ice that was between $1.05-1.15 \mathrm{~m}$ thick at test sites. A total of 6 sites were used to collect data and input acoustic energy into the air, ice, or water. Sites 1, 2, and 3 were receiver locations and sites 4, 5, and 6 were source locations (Figure 1, Table 1). Exact positioning of sites with respect to GPS, the coast line, and open water line are reported in Table 2.

The sea ice conditions varied significantly throughout the test area (Figure 2). At the cluster of sites 1,4 , and 5 , the ice was relatively flat, without any large ridges. At the cluster of sites 2,3 , and 6 , the ice was also flat, but was surrounded on all sides by large ice ridges. The largest of these ridges was near site 3 and was approximately $5 \mathrm{~m}$ high. It was suspected that some of the large ice ridges may have been ground-fast because the water was only 8-12 m deep, however, this was not confirmed. The space between the two site clusters was moderately covered with smaller ice ridges $2-3 \mathrm{~m}$ high. The choice of the test locations were simply made by picking where there was flat enough ice to facilitate ease of access and deployment of equipment. Ice ridges were avoided as much as possible, however, large open areas of ice, without ridges, were quite sparse in the shore-fast environment.

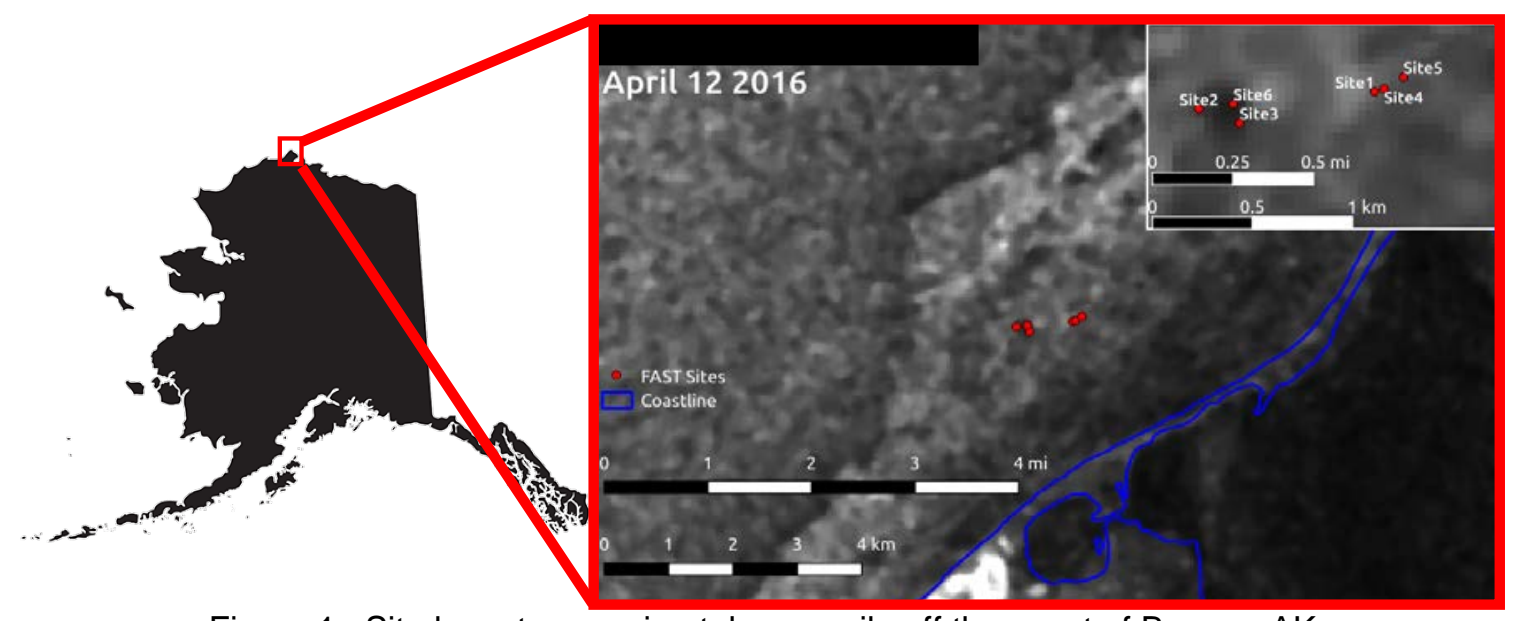

Figure 1. Site layout approximately one mile off the coast of Barrow, AK. 
(a)

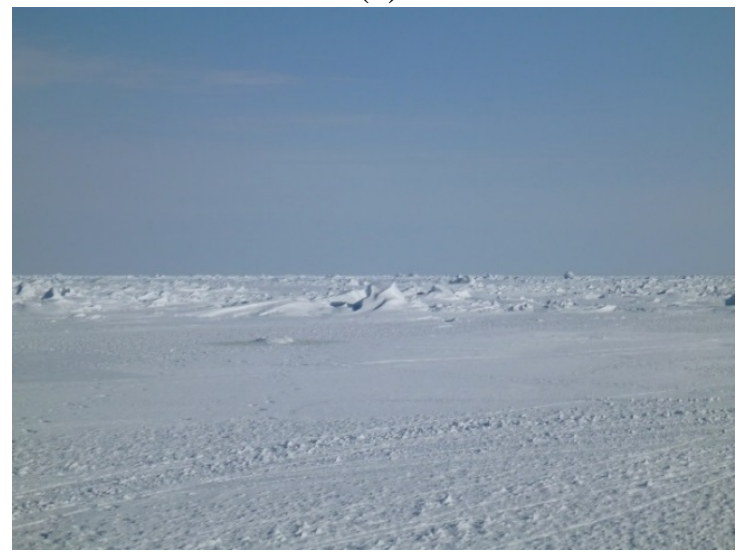

(c)

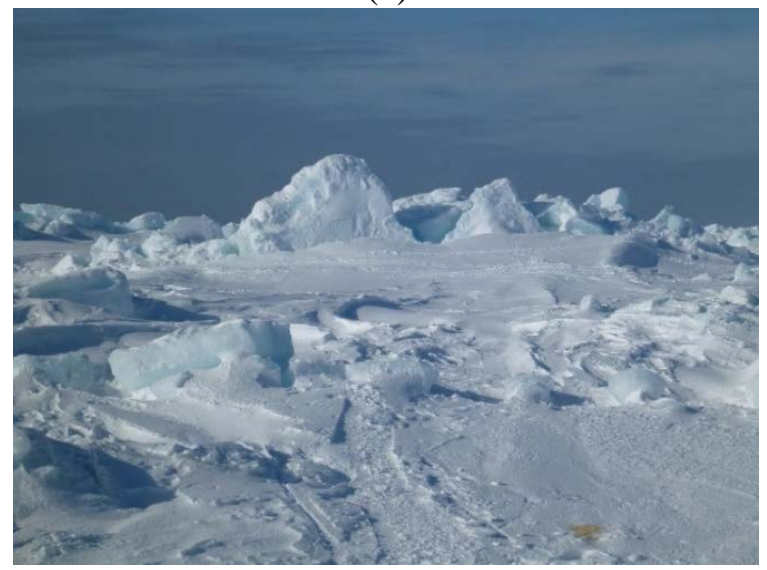

(e)
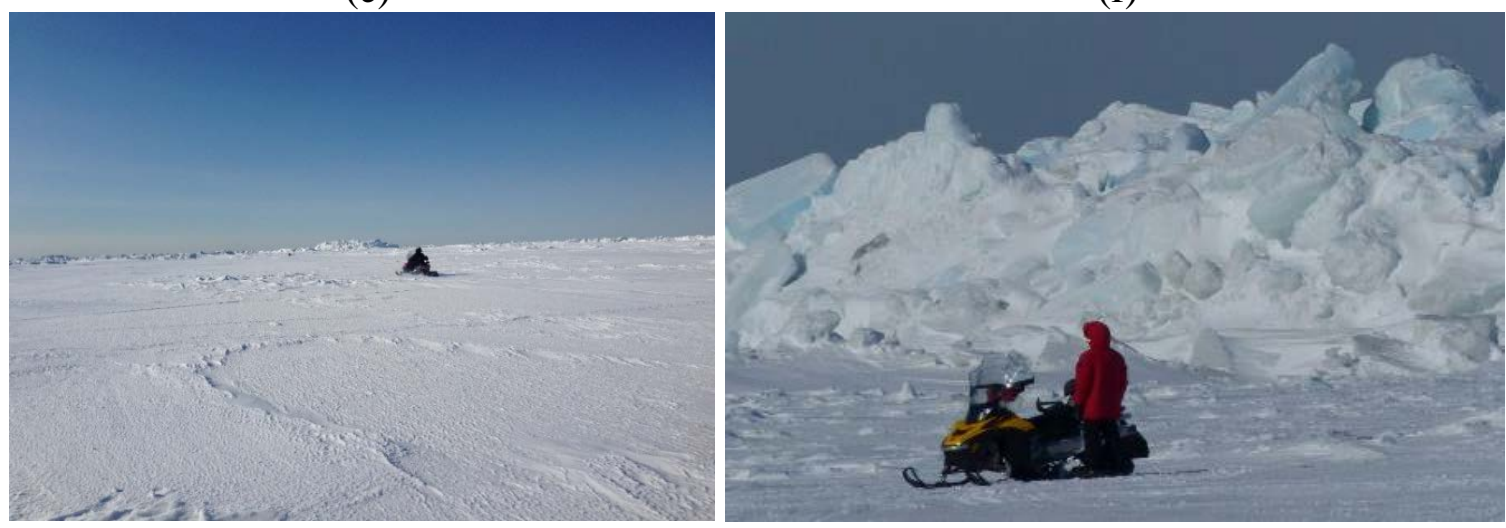

(b)

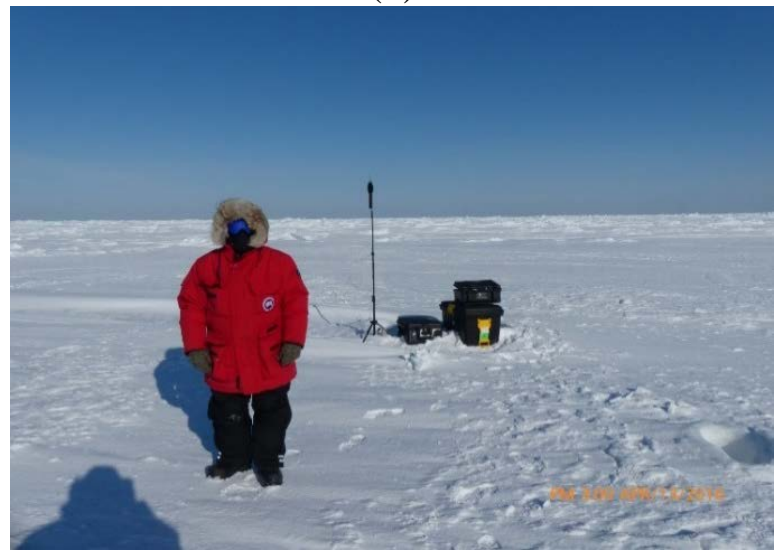

(d)

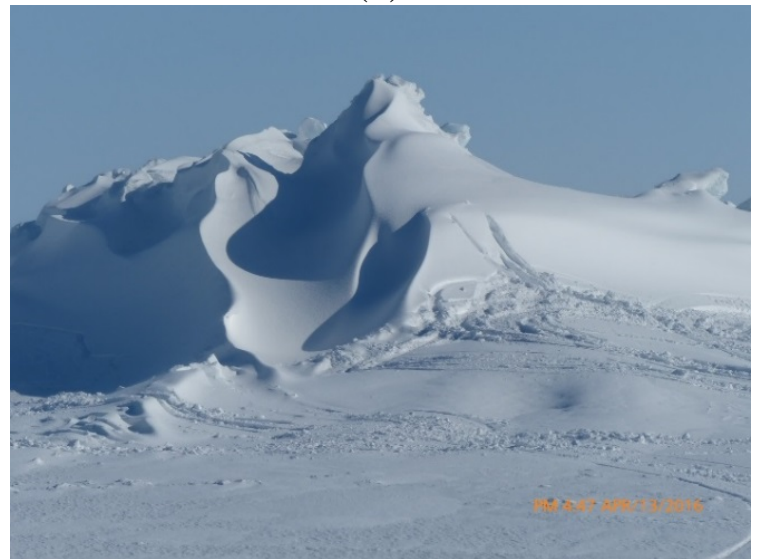

(f)

Figure 2. Shore-fast sea ice conditions near the test sites: (a) Site 1 looking towards site 4. (b) Site 1 looking seaward. (c) Photograph from cluster of sites 2, 3, and 6 looking east towards sites 1, 4, and 5. (d) Large ice ridge near site 3. (e) Site 2 looking towards site 3. (f) Scale of large ice ridges compared to a person. Large ice ridges were approximately $5 \mathrm{~m}$ high.

At source locations, data was collected with a headless, 4-slot, National Instruments (NI) cRIO-9024. The data acquisition modules used were NI-9234, NI-9269, NI-9467, and NI9344. These modules were used for acoustic data collection, signal output (as necessary), GPS location and timing signal acquisition, and system control, respectively. At receiver 
locations, data was collected with a 4-slot, cRIO-9031. Three NI-9234 modules were used to collect acoustic data and one NI-9467 module was used for GPS location and timing signal acquisition. All acoustic data were sampled at $51200 \mathrm{~Hz}$ in blocks of 120 seconds. GPS time and position data were sampled once at the beginning of every data collection. Source and receiver data collections were time synchronized via GPS timing signals.

Table 1. Distance between source and receiver sites in meters

\begin{tabular}{|c|c|c|c|c|}
\hline & \multicolumn{3}{|c|}{ Receiver Sites } \\
\hline & & SITE 1 & SITE 2 & SITE 3 \\
\hline \multirow{3}{*}{ 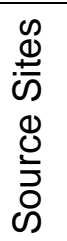 } & SITE 4 & 50.32 & 929.93 & 743.21 \\
\hline & SITE 5 & 164.32 & 1034.74 & 853.23 \\
\hline & SITE 6 & 703.49 & 117.45 & 105.29 \\
\hline
\end{tabular}

\subsection{SOURCES}

The different types of sources used to excite the air, ice, or water for various experiments are described here.

A propane cannon (Zon Mark 4) was used as an in-air acoustic source. The detonation of propane created an impulsive pressure wave originating at the source location. The cannon did not shoot a projectile. A mechanical regulator was used to automatically fire the cannon one time approximately every 30 seconds. The regulator was set so that as many shots as possible could be recorded during the 120 second measurement period. Location of the cannon was approximately $2.8 \mathrm{~m}$ from the microphone at the source site for all experiments.

An instrumented force hammer (PCB Model 086D50, $0.23 \mathrm{mV} / \mathrm{N}$ ) was used to input energy to the ice sheet. The hammer excited the ice sheet modal response and measured the force input to the ice sheet. For experiments that the force hammer was used, the ice was struck directly (i.e. no post was frozen into the ice to transmit the hammer impact). Location of hammer impact in relation to the source transducers changed between experiments. This was necessary to find a relatively smooth and solid patch of ice to impact. At source locations where multiple hammer experiments were conducted, the ice would inevitably become chipped and non-uniform. Therefore, it was necessary to move locations slightly between experiments. For all experiments, the hammer impact location was between approximately 1-3 m from the source geophone. During the 120 second measurement period, the ice was impacted with the force hammer as many times as was feasible (usually between 30 to 40 times). Any hits that were of poor quality (double hits and overloaded signals) were removed during post processing. This resulted in 10-20 "good" hammer impacts per recording that could be used for spectral averaging. 
An underwater speaker (Lubell Labs Model LL916) was used as an underwater acoustic sound source. The speaker produced tones at various frequencies $(200,400,800,1600$, $6400 \mathrm{~Hz}$ ) and short chirps across frequency ranges $(40-2500 \mathrm{~Hz}$ and $4000-25000 \mathrm{~Hz})$. The tones and chirps were played over the 120 second measurement period. Each tone duration was approximately 10 seconds and each chirp duration was approximately 0.01 seconds. An amplifier (PylePro PZR 600) was used to drive the underwater speaker and maintain consistent sound levels between experiments.

\subsection{SOURCE TRANSDUCERS}

In order to quantify the source levels, one microphone (PCB 377B02, $50 \mathrm{mV} / \mathrm{Pa}$ ), one single-axis geophone (Mark Products $19.7 \mathrm{~V} /(\mathrm{m} / \mathrm{s})$ ), and one hydrophone (Teledyne Reson TC 4032, -170 dB re $1 \mathrm{~V} / \mu \mathrm{Pa}$ ) were placed near the source. The microphone was placed approximately $70 \mathrm{~cm}$ above the ice at source locations.

It should be noted for experiments when the cannon was used, the pressure wave overloaded the in-air microphone at the source site. A spare hydrophone (TC 4032) was placed at original the microphone position. The hydrophone was used to record the in-air acoustic wave for cannon experiments. For simplicity, and to avoid confusion, we will refer to any in-air measurements as microphone measurements.

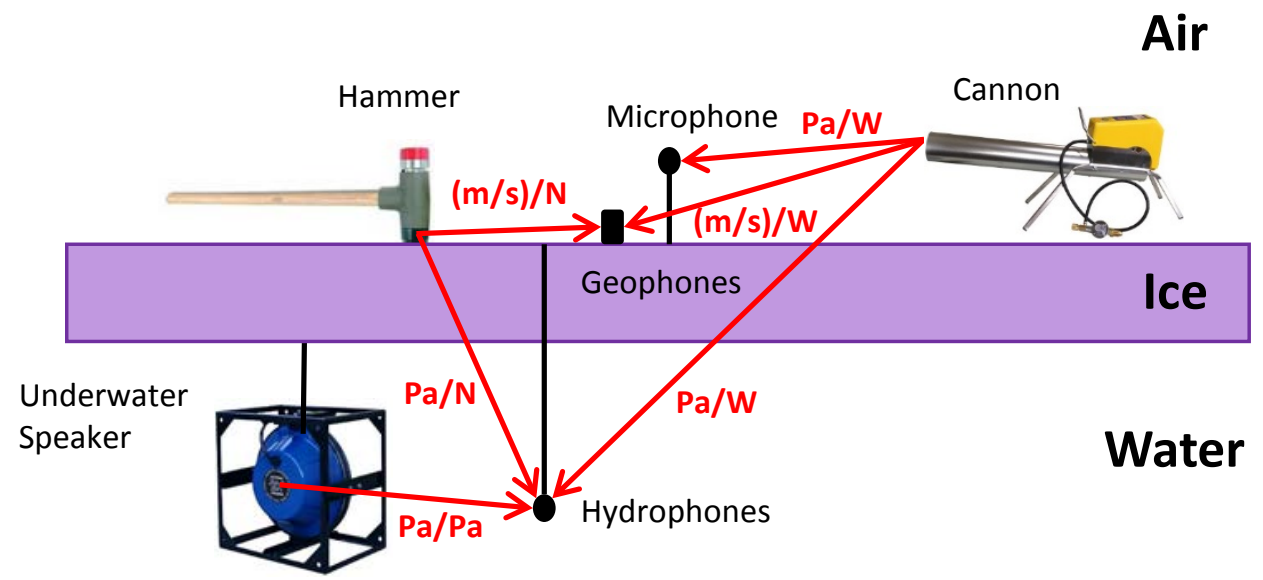

Figure 3. Source location schematic of various acoustic sources and receivers. Arrows indicate measurements between source and receiver with adequate signal-to-noise ratio. Units of output signal over input signal are indicated.

\subsection{RECEIVERS}

At each receiver location, several transducers were placed to simultaneously record the acoustic response from the source excitation. One microphone (PCB 378B02, $50 \mathrm{mV} / \mathrm{Pa})$, one three-axis geophone (GS-One $3-C, 85.8 \mathrm{~V} /(\mathrm{m} / \mathrm{s})$ ), and five hydrophones (Teledyne Reson TC 4013, -211 dB re $1 \mathrm{~V} / \mu \mathrm{Pa}$ ) were used at each receiver location to measure the in-air sound pressure level (SPL), ice vibrational velocity, and underwater SPL respectively. The microphone, geophone, and one hydrophone were centrally located at the site. Four additional hydrophones were placed roughly at North, East, South, and West, 
approximately $3 \mathrm{~m}$ from the center of the site. The hydrophones were placed at a depth of $5 \mathrm{~m}$ underwater through drilled holes in the ice (Figure 4). For purposes of this paper, only the centrally located hydrophone is analyzed. 
Table 2. Summary of source and receiver site location, conditions, and transducer position.

\begin{tabular}{|c|c|c|c|c|c|c|c|c|c|c|}
\hline $\begin{array}{l}\text { Site } \\
\text { No. }\end{array}$ & $\begin{array}{l}\text { Source/ } \\
\text { Receiver }\end{array}$ & Lat./Lon. & $\begin{array}{l}\text { Water } \\
\text { Depth } \\
(\mathrm{m})\end{array}$ & $\begin{array}{l}\text { Distance } \\
\text { From } \\
\text { Shore } \\
(\mathrm{km})\end{array}$ & $\begin{array}{c}\text { Distance } \\
\text { From } \\
\text { Open } \\
\text { Water } \\
(\mathrm{km})\end{array}$ & $\begin{array}{c}\text { Ice } \\
\text { Thickness } \\
(\mathrm{m})\end{array}$ & $\begin{array}{l}\text { Snow } \\
\text { Thickness } \\
\text { (cm) }\end{array}$ & $\begin{array}{l}\text { Microphone } \\
\text { Height (m) }\end{array}$ & $\begin{array}{l}\text { Hydrophone } \\
\text { Depth (m) }\end{array}$ & $\begin{array}{l}\text { Underwater } \\
\text { Source Depth } \\
\text { (m) }\end{array}$ \\
\hline 1 & Receiver & $\begin{array}{l}\text { N 71.36681, } \\
\text { W 156.61540 }\end{array}$ & 9.5 & 2.18 & 2.63 & 1.03 & 2.5 & 2 & 5 & NA \\
\hline 2 & Receiver & $\begin{array}{l}\text { N 71.36630, } \\
\text { W 156.64004 }\end{array}$ & 12.8 & 2.52 & 1.67 & 1.15 & 3 & 2 & 5 & NA \\
\hline 3 & Receiver & $\begin{array}{l}\text { N 71.36557, } \\
\text { W 156.63444 }\end{array}$ & 11.0 & 2.36 & 1.93 & 1.07 & 3 & 2 & 5 & NA \\
\hline 4 & Source & $\begin{array}{l}\text { N 71.36693, } \\
\text { W 156.61404 }\end{array}$ & 8.0 & 2.18 & 2.64 & 1.05 & 2.5 & 0.7 & 2.3 & 1.9 \\
\hline 5 & Source & $\begin{array}{l}\text { N 71.36745, } \\
\text { W 156.61125 }\end{array}$ & 8.4 & 2.2 & 2.75 & 1.05 & 2.5 & 0.7 & 2.5 & 2.1 \\
\hline 6 & Source & $\begin{array}{l}\text { N 71.36649, } \\
\text { W 156.63521 }\end{array}$ & 10.7 & 2.48 & 1.88 & 1.05 & 2.5 & 0.7 & 2.6 & 1.7 \\
\hline
\end{tabular}




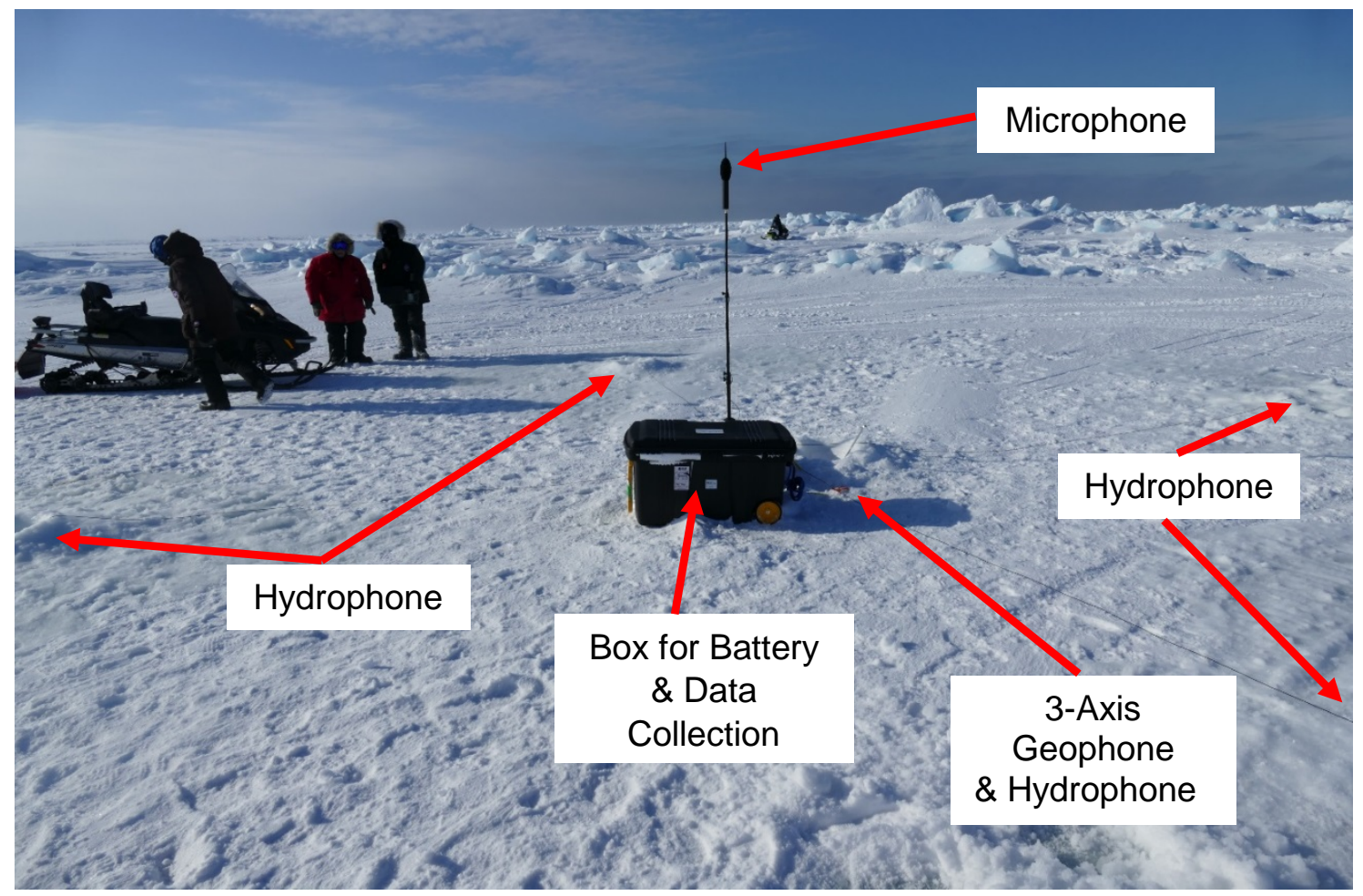

Figure 4. Receiver site transducer layout (Site 1 shown).

\section{RESULTS AND DISCUSSION}

\subsection{TEMPORAL PROPAGATION}

At the outset of our analysis, it was necessary to determine the receivers which had adequate signal-to-noise ratio (SNR) for any given experiment. Examining the spatial and temporal propagation, also gave us an indication of which frequency ranges and distances could be used for future detection and tracking applications. Figures 5-9 show the power spectral densities (PSD) as a function of both frequency and time measured at the source location and at selected receiver locations. The time scale on these plots is zoomed in to focus on only a few source inputs from the 120 second acquisition time. This was done for greater clarity of the temporal propagation.

For the hammer source experiment (Figures 5, 6), the force input to the ice, as well as the geophone and hydrophone responses are investigated. Note that microphone data in response to hammer excitation was not included due to lack of SNR. At $50 \mathrm{~m}$ from the source (Figure $5(\mathrm{~d})$ ), the geophone has some detectable response especially at low frequencies (less than $200 \mathrm{~Hz}$ ). It comes as no surprise that low frequencies propagate well in the ice and mid-high frequencies are attenuated quite rapidly. At the $164 \mathrm{~m}$ site, there is almost no detectable signal in the geophone. By comparison, mid-high frequencies propagate better through the water and can be seen much more clearly in both the $50 \mathrm{~m}$ and $164 \mathrm{~m}$ sites. In general, it can be said that the water path transmits energy farther than the ice path for a direct input to the ice. 
The in-air temporal propagation of the cannon blast is seen in Figure 7. Adequate SNR is noted at all receiver distances including the $1035 \mathrm{~m}$ site. In Figure 7 (c\&d), two large signal indications are visible between $1.4 \mathrm{sec}$ to $3.3 \mathrm{sec}$, before the arrival of the in air pressure wave at approximately $4.5 \mathrm{sec}$ and $5.1 \mathrm{sec}$ respectively. During the cannon experiment, a hand-held two-way radio was held near the cannon and near the receiver microphones. As the cannon was about to fire, the transmitting (push-to-talk) feature of the source radio was activated. This transmitted the cannon sound via radio waves, which obviously arrived much earlier than the in-air pressure wave. Following the radio start indication, the in-air pressure wave can be seen at the receiver locations. Based on the time delay between the source and receiver sites, the in-air sound speed was determined to be approximately $331 \mathrm{~m} / \mathrm{s}$. This is approximately $4 \mathrm{~m} / \mathrm{s}$ faster than the speed of sound determined from the well-know Equation 1 [34], which is based on the ratio of specific heats $(\gamma)$, the gas constant $(R)$, and the air temperature $\left(T_{k}\right)$. The higher measured speed of sound is likely because the receivers were down-wind from the cannon blast, decreasing the time of flight (i.e. increasing sound speed). Wind speeds varied between $3.9 \mathrm{~m} / \mathrm{s}$ to $22.8 \mathrm{~m} / \mathrm{s}$ during our testing.

$$
c=\sqrt{\gamma R T_{k}}
$$

The low frequency (40 -2500 Hz) chirps produced by the underwater source (Figure 8) were detectable at the $164 \mathrm{~m}$ and the $853 \mathrm{~m}$ site. However, there was much lower SNR at the $853 \mathrm{~m}$ site. Similar results were seen for the high frequency $(4000-25000 \mathrm{~Hz})$ chirps. Based on the time delay between the source and receiver sites for the underwater speaker chirps, the average underwater sound speed was determine to be approximately $1441 \mathrm{~m} / \mathrm{s}$. The hydrophone responses to the cannon blast in air (Figure 9) also confirm an average underwater sound speed of $1441 \mathrm{~m} / \mathrm{s}$. There was limited SNR for the hydrophones at $1035 \mathrm{~m}$ from the cannon source. It is interesting to note in Figure 9 (b), that there are signals which are present before the arrival of the underwater sound wave. These indicate sound waves which traveled through the ice. Additionally, there are several signals after the arrival of the underwater sound wave which indicate reflections and scattering from the underwater environment. These reflections and scattering are expected due to the irregular ice ridges near sites 2 and 3.

While the time of flight approach to determine sound speed in the water is not rigorous, the average sound speed was also measured directly with a SonTek CastAway conductivity, temperature, and depth (CTD) probe (Figure 10). From the CTD data, the sound speed underwater ranged from $1433 \mathrm{~m} / \mathrm{s}$ to $1446 \mathrm{~m} / \mathrm{s}$ for various depths, with an average of $1441 \mathrm{~m} / \mathrm{s}$. The underwater sound speed profile was calculated by the CastAway CTD using the Chen-Millero method [35, 36].

For purposes of processing beyond this point, we did not include any data which did not have at least $10 \mathrm{~dB}$ of signal-to-noise ratio. 

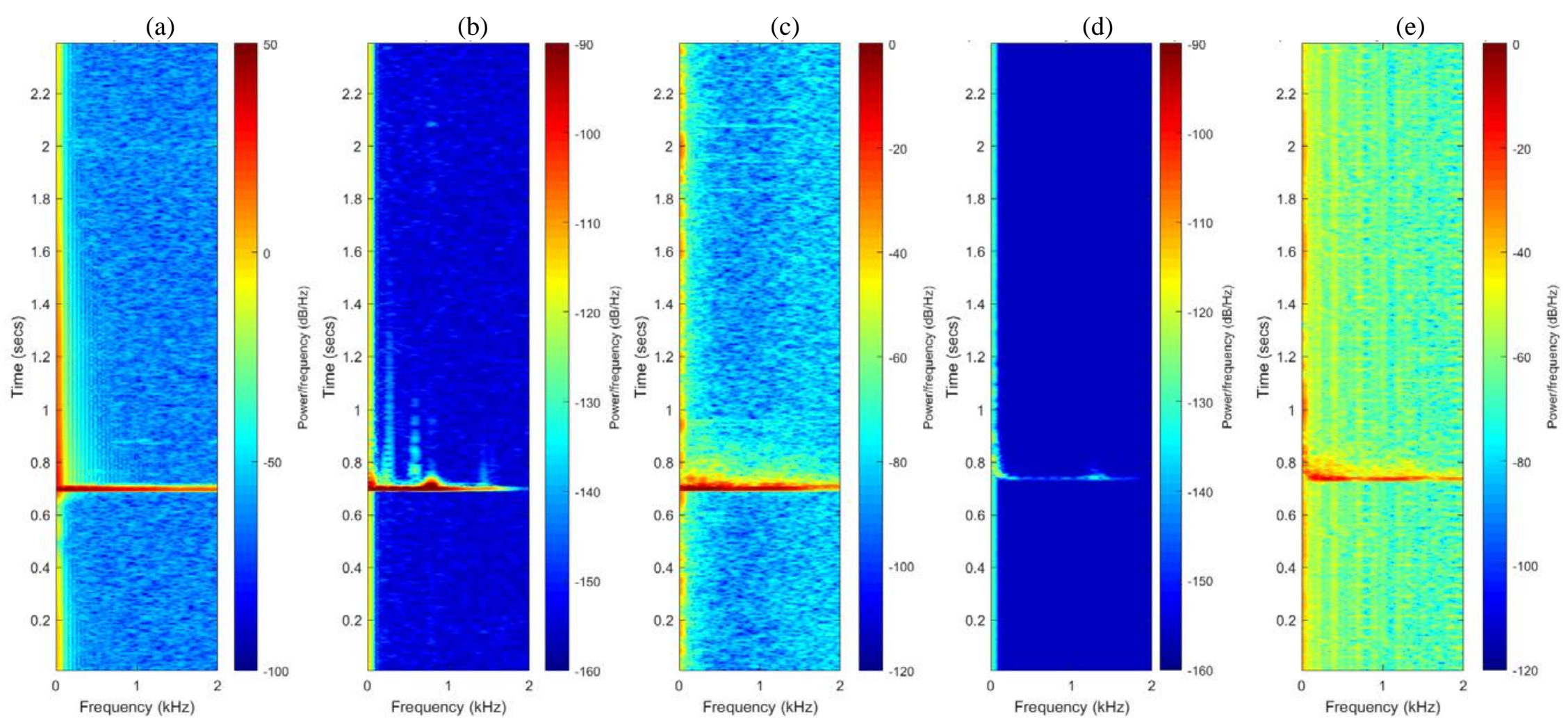

Figure 5. Ice-to-ice and ice-to-water temporal propagation. Source (site 4) to receiver (site 1 ) distance approximately $50 \mathrm{~m}$. (a) Hammer force input ( $\mathrm{dB}$ re $1 \mathrm{~N} / \mathrm{Hz}$ ) at site 4 source location. (b) Geophone response $(\mathrm{dB}$ re $1 \mathrm{~m} / \mathrm{s} / \mathrm{Hz}$ ) at site 4 source location. (c) Hydrophone response (dB re $1 \mathrm{~Pa} / \mathrm{Hz}$ ) at site 4 source location. (d) Geophone response $(\mathrm{dB}$ re $1 \mathrm{~m} / \mathrm{s} / \mathrm{Hz})$ at site 1 receiver location. (e) Hydrophone response (dB re 1 $\mathrm{Pa} / \mathrm{Hz})$ at site 1 receiver location. 


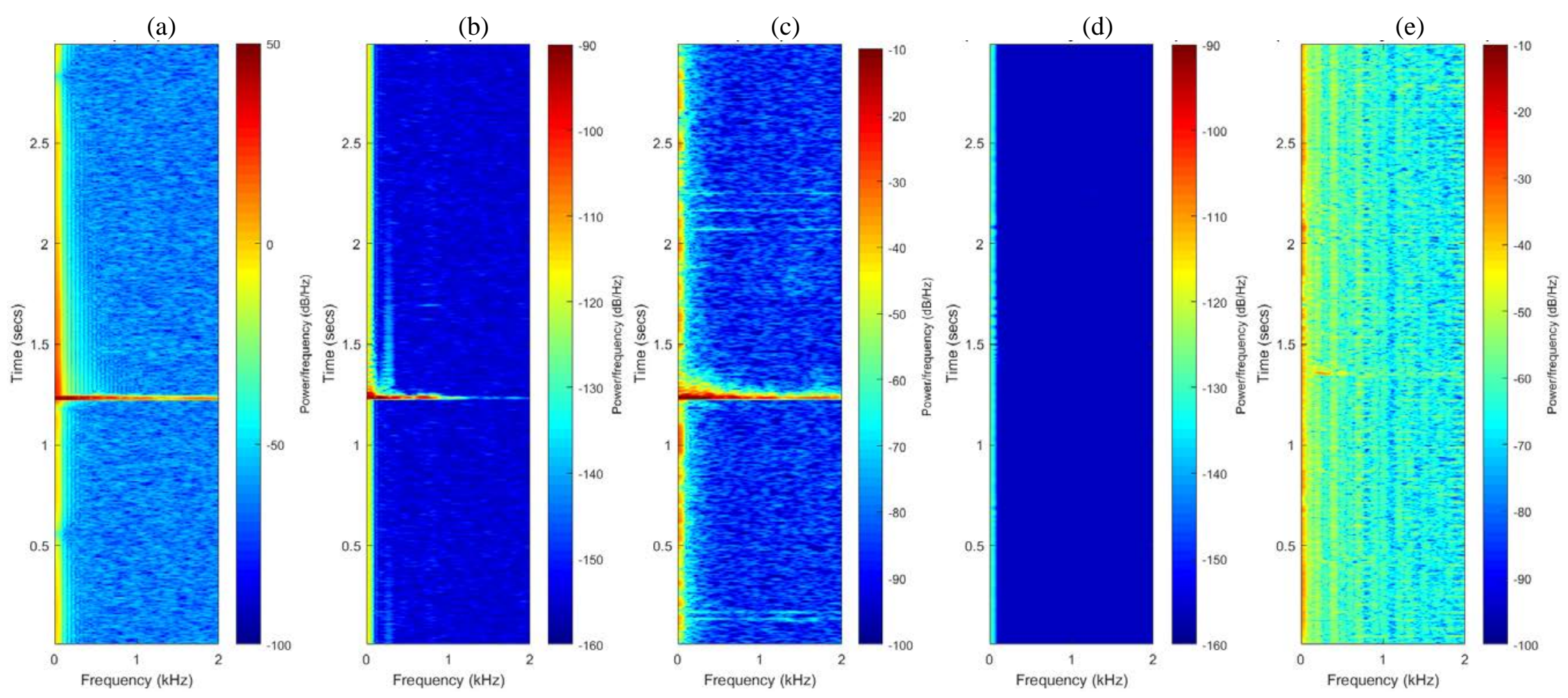

Figure 6. Ice-to-ice and ice-to-water temporal propagation. Source (site 5) to receiver (site 1) distance approximately $164 \mathrm{~m}$. (a) Hammer force input ( $d B$ re $1 \mathrm{~N} / \mathrm{Hz}$ ) at site 5 source location. (b) Geophone response (dB re $1 \mathrm{~m} / \mathrm{s} / \mathrm{Hz}$ ) at site 5 source location. (c) Hydrophone response (dB re $1 \mathrm{~Pa} / \mathrm{Hz}$ ) at site 5 source location. (d) Geophone response $(\mathrm{dB}$ re $1 \mathrm{~m} / \mathrm{s} / \mathrm{Hz}$ ) at site 1 receiver location. (e) Hydrophone response (dB re 1 $\mathrm{Pa} / \mathrm{Hz}$ ) at site 1 receiver location. 
(a)

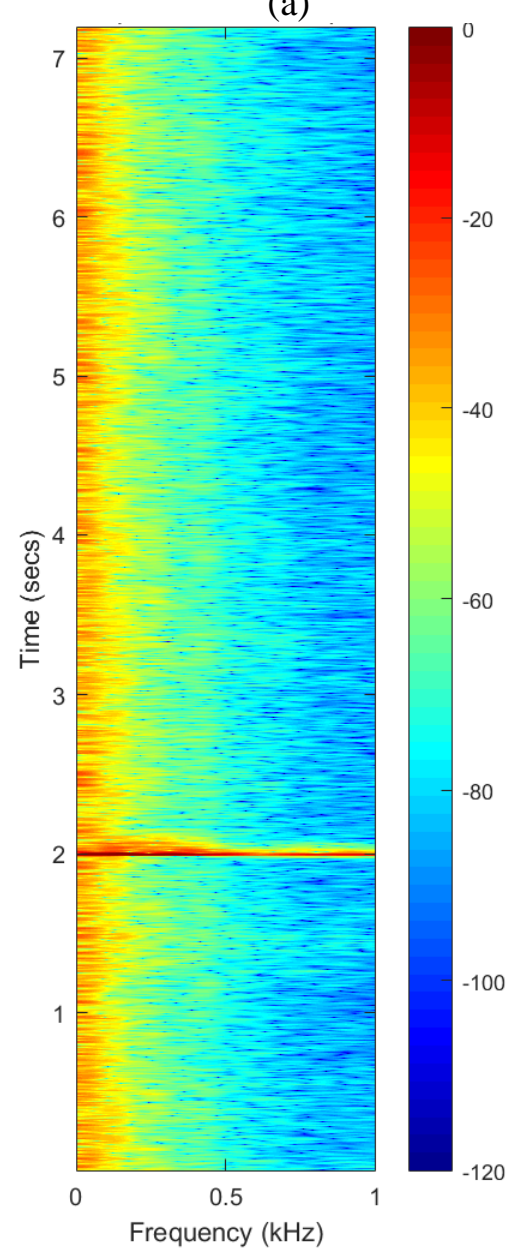

(b)

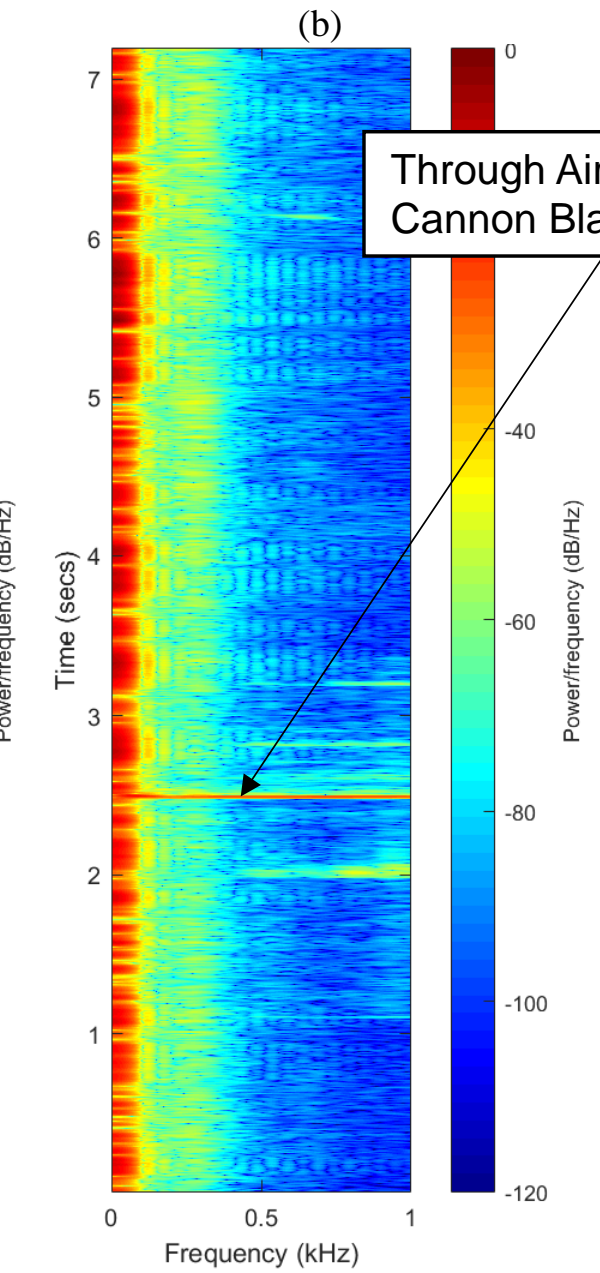

(c)

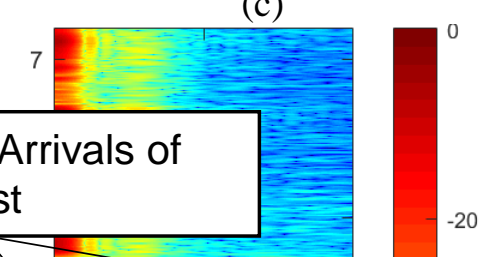

$$
\text { Frequency (kHz) }
$$

(d)
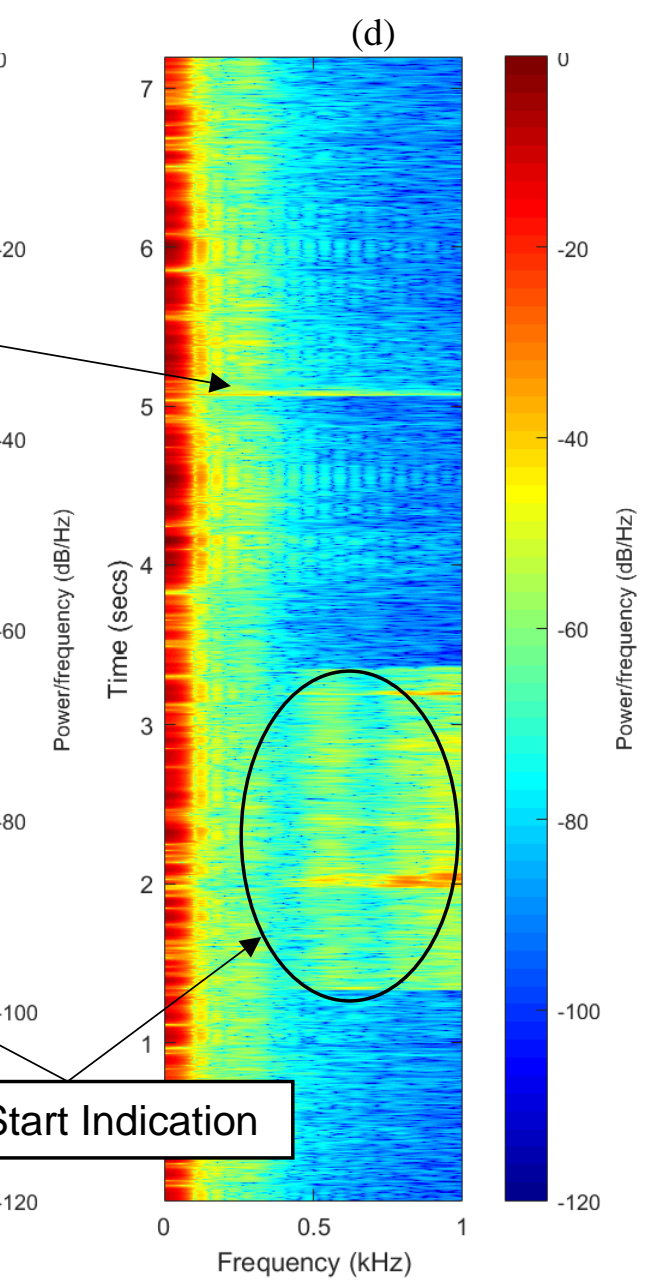

Figure 7. Air-to-air temporal propagation from the cannon source to the microphones at various receiver distances. (a) In air sound level at source location (site 5) normalized to $1 \mathrm{~m}$. (b) In air sound level at site 1 approximately $164 \mathrm{~m}$ from source. (c) In air sound level at site 3 approximately $853 \mathrm{~m}$ from source. (d) In air sound level at site 2 approximately $1035 \mathrm{~m}$ from source. (All levels: $\mathrm{dB}$ re $1 \mathrm{~Pa} / \mathrm{Hz}$ ) 
(a)

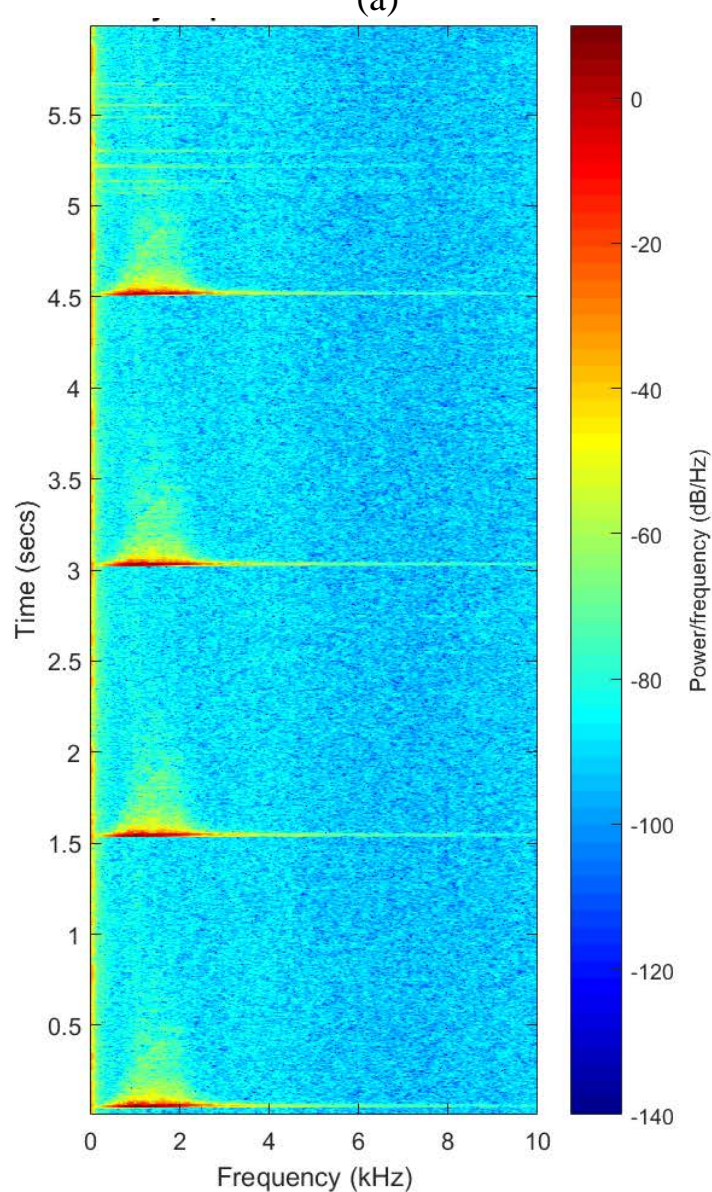

(b)

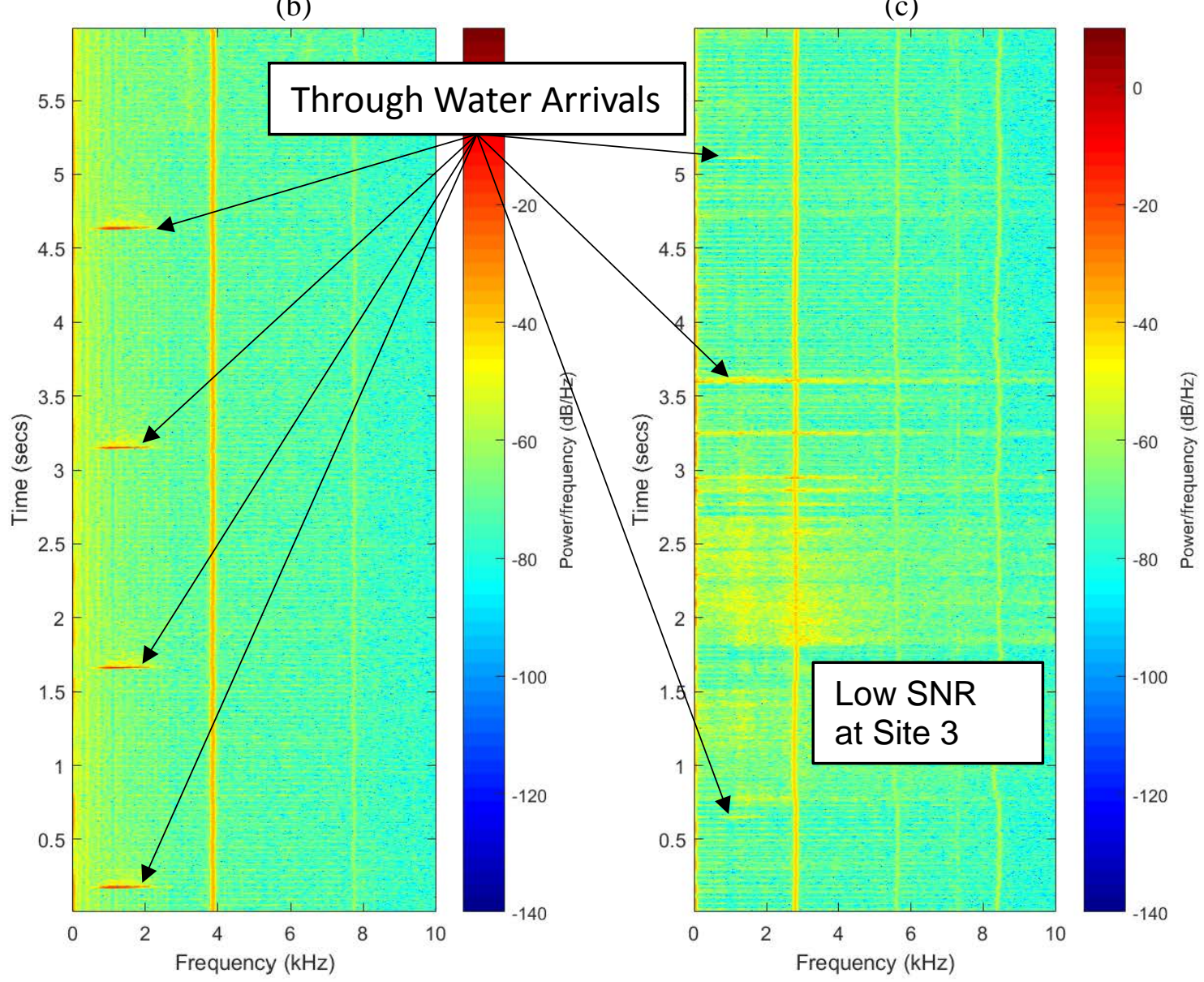

Figure 8. Water-to-water temporal propagation from the underwater speaker to the hydrophones at various receiver distances. (a) Underwater sound level at source location (site 5) normalized to $1 \mathrm{~m}$. (b) Underwater sound level at site 1 approximately $164 \mathrm{~m}$ from source. (c) Underwater sound level at site 3 approximately $853 \mathrm{~m}$ from source. (All levels: $\mathrm{dB}$ re $1 \mathrm{~Pa} / \mathrm{Hz}$ ) 
(a)

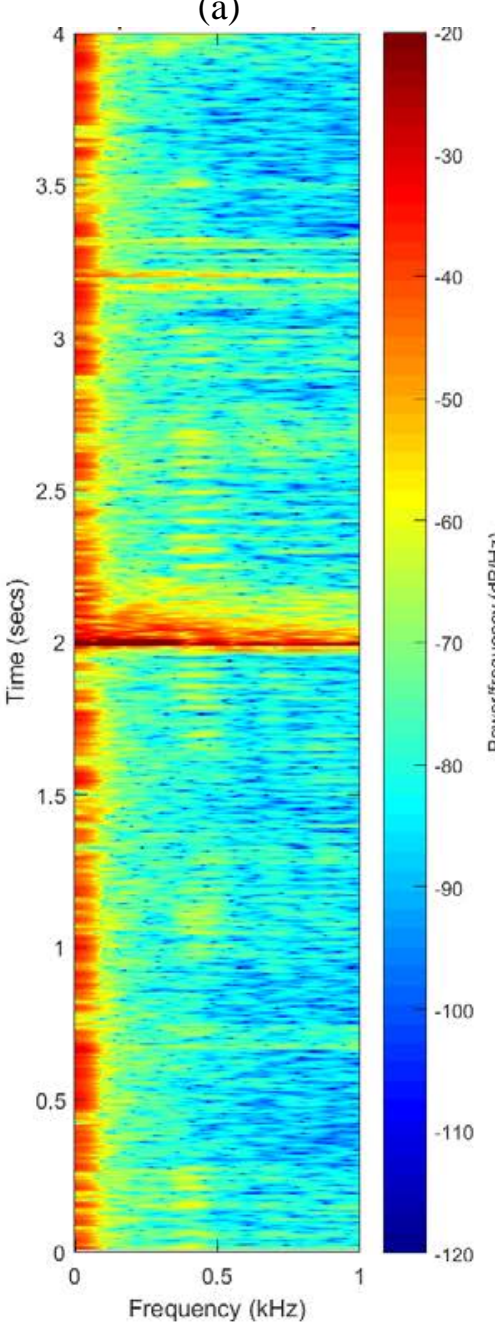

(b)

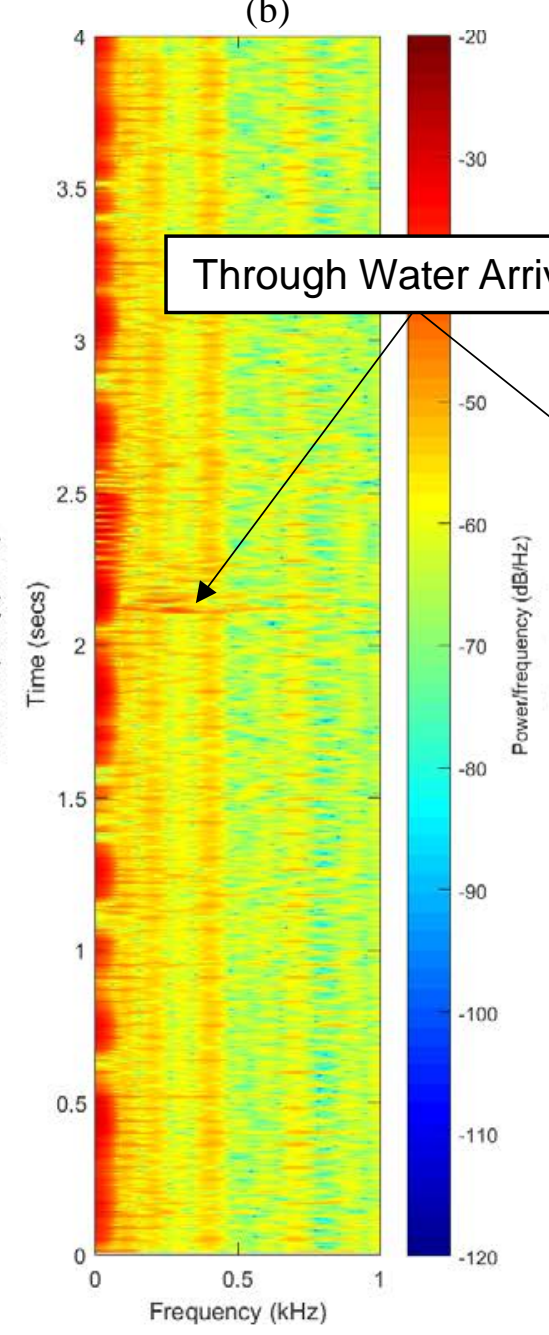

(c)

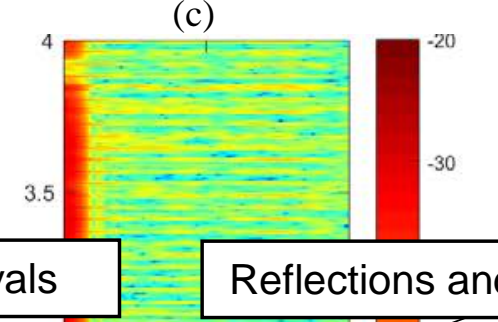

3
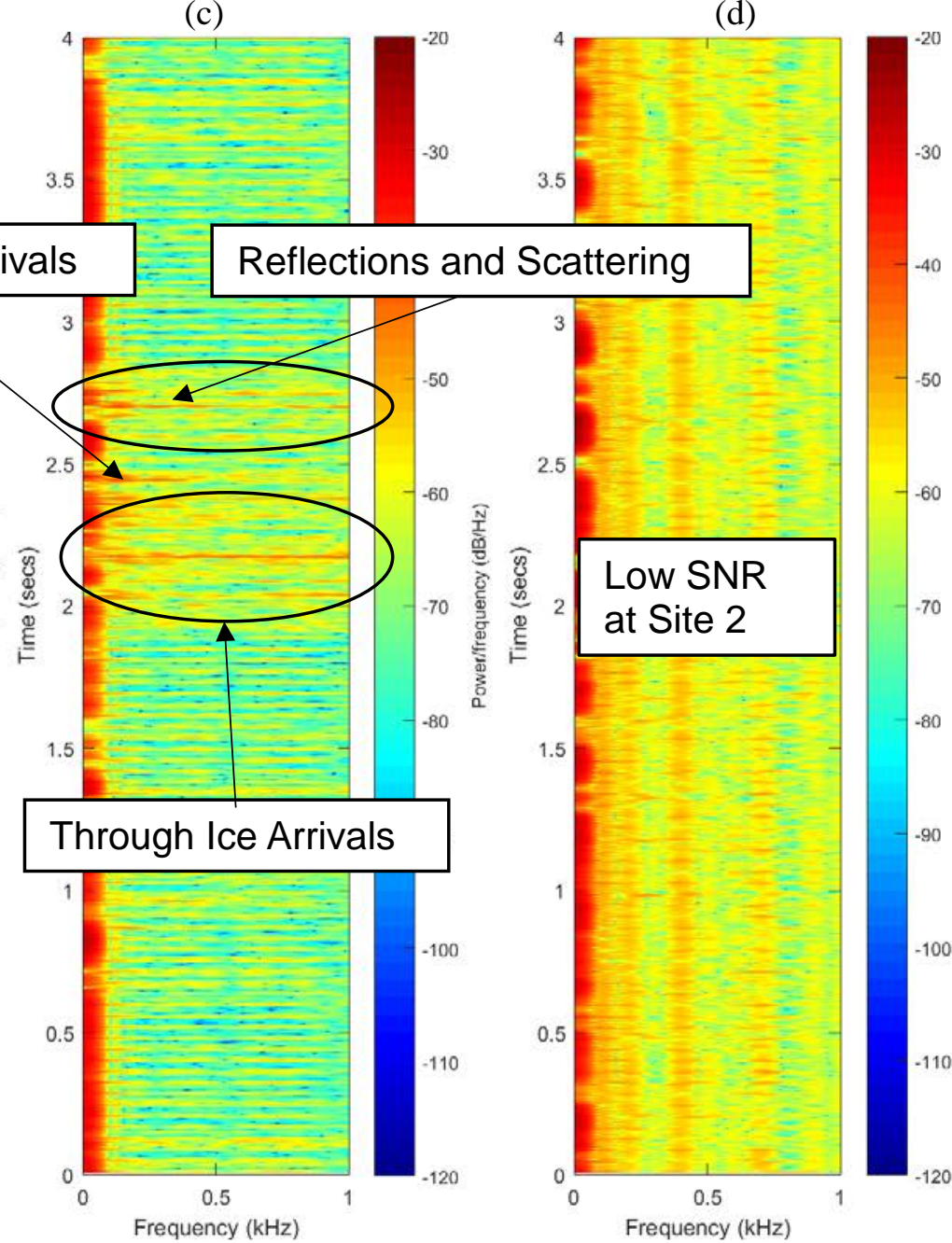

Frequency $(\mathrm{kHz})$

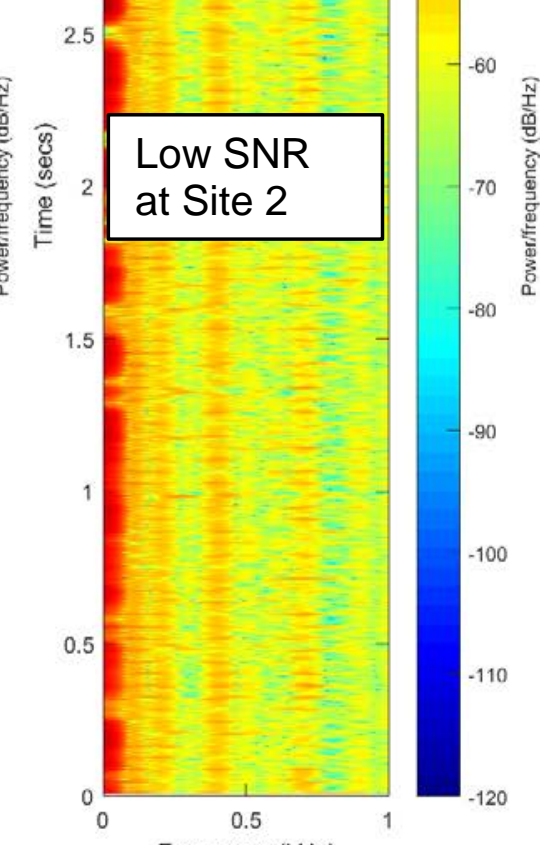

Figure 9. Air-to-ice-to-water temporal propagation from the cannon source to the hydrophones at various receiver distances. (a) Underwater sound level at site 5. (b) Underwater sound level at site 1 approximately $164 \mathrm{~m}$ from source. (c) Underwater sound level at site 3 approximately $853 \mathrm{~m}$ from source. (d) Underwater sound level at site 2 approximately $1035 \mathrm{~m}$ from source. (All levels: $\mathrm{dB} \mathrm{re} 1 \mathrm{~Pa} / \mathrm{Hz}$ ) 

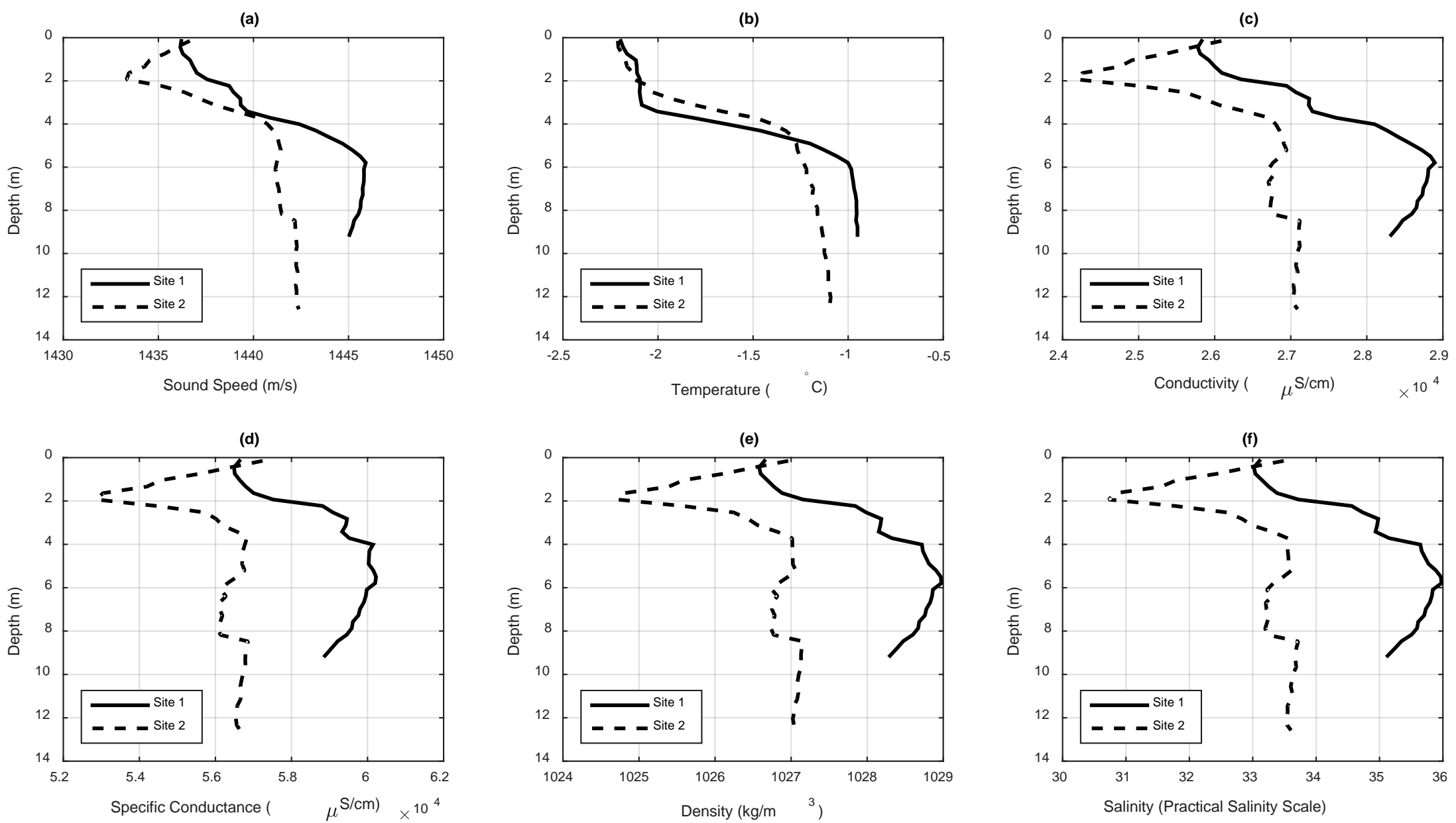

Figure 10. Depth profiles measured with conductivity, temperature, and depth (CTD) probe for sites 1 and 2. Measurements taken on 12/04/16 at UTC 15:53:32 and UTC 17:07:47 for sites 1 and 2 respectively. 


\subsection{CALCULATIONS}

From the calibrated time data for each experiment, the linear spectra of the source $\left(S_{x}\right)$ and the linear spectra of the receivers $\left(S_{y}\right)$ were determined by computing the Fast Fourier Transform (FFT) in Matlab. Using the linear spectra, the autopower spectra $\left(G_{x x}\right)$, crosspower spectra $\left(G_{y x}\right)$, and Frequency Response Functions (FRF) between source and receiver were determined (Equations 2-4) [32, 37].

The autopower spectra of the source was computed by multiplying the linear spectra by its complex conjugate. The crosspower spectra between the source and the receiver was computed by multiplying the linear spectra of the source by the conjugate linear spectra of the receiver. Finally, the FRF was computed by dividing the crosspower by the autopower spectra. The FRF is defined as the output signal (response) divided by the input signal (source) in the frequency domain. Since the crosspower spectra is able to average out uncorrelated components, the noise on the response is minimized in our FRF calculations.

$$
\begin{gathered}
G_{x x}(\omega)=S_{x}^{*}(\omega) S_{x}(\omega) \\
G_{y x}(\omega)=S_{y}^{*}(\omega) S_{x}(\omega) \\
F R F(\omega)=\frac{G_{y x}(\omega)}{G_{y y}(\omega)}
\end{gathered}
$$

To determine the effectiveness of the FRF, an accompanying function, coherence (COH), was calculated [32, 37]. Coherence relates the amount of the output signal that is linearly related to the input signal. The coherence function ranges from zero to one, where one represents $100 \%$ of the output signal being linearly related to the input signal and zero represents $0 \%$ of the output signal being linearly related to the input signal. In general, it is preferable to see coherence which is close to one at frequencies where the FRF is to be investigated. Coherence less than one can be caused by non-linearity in the system, unmeasured inputs to the system (noise), an anti-resonance in the system, bias errors in the measurement, or some combination of all of these reasons. The coherence for our measurements will be investigated alongside the FRFs.

$$
\operatorname{COH}(\omega)=\frac{G_{x y}(\omega) G_{y x}(\omega)}{G_{x x}(\omega) G_{y y}(\omega)}
$$

\subsection{HAMMER EXPERIMENT FRFs}

For hammer experiments, there were many hammer hits over the 120 second measurement period with various timing between hits and force input with the hammer. Only "good" hammer hits were used for post processing. Hammer hits were not included if the signal was overloaded or if there was a double hit. Note that a double hit was registered any time that the hammer struck the ice more than one time per swing. Blocks of data, 1 second in duration and containing a good hammer hit signal, were used to compute the autopower 
spectra. All of the autopower spectra for a given experiment were then averaged. The averaged autopower spectra for the hammer experiments can be seen in Figure 11. There is effective input energy between approximately $1 \mathrm{~Hz}-200 \mathrm{~Hz}$ because the autopower spectra is high enough to excite a system response and there is good coherence in this frequency range. At $200 \mathrm{~Hz}$ and above the autopower spectra begins to roll off at a rate of approximately $-40 \mathrm{~dB}$ per octave. Beyond $2 \mathrm{kHz}$, the input autopower spectra is too low (less than $-10 \mathrm{~dB}$ ) to excite any system responses. Additionally, coherence between the source and receiver begins to suffer due to low input energy above $1 \mathrm{kHz}$.

The drive point FRF and $\mathrm{COH}$ between the hammer input and the geophone response at the source site (drive point mobility) is shown in Figure 12(a). It can be seen that there is a large peak in the FRF at approximately $800 \mathrm{~Hz}$ and a corresponding harmonic at 1600 $\mathrm{Hz}$. The $800 \mathrm{~Hz}$ peak and its harmonic correspond to the through-thickness compressional mode of the ice sheet. We have assumed that the through-thickness mode in the ice is behaving like a quarter-wavelength resonance due to a high impedance at the water interface and low impedance at the air interface. It is well known for quarter-wavelength resonators, that frequency $(f)$ is related to the wave velocity $\left(v_{p}\right)$ and the wavelength by Equation 6 [38]. We can set $L$ equal to the ice thickness which was $1.05 \mathrm{~m}$ at the drive point locations. Also, for the $800 \mathrm{~Hz}$ mode, we can set $n$ equal to 1 .

$$
f=\frac{(2 n-1) v_{p}}{4 L}
$$

Solving for the compressional wave velocity in the ice, we can determine $v_{p}$ is approximately equal to $3360 \mathrm{~m} / \mathrm{s}$. This is similar to the compressional wave speed reported by several other sources $[8,10,13]$.

To confirm that the measured drive point mobility is reasonable, the theoretical infinite plate mobility can be plotted for comparison. To approximate the theoretical mobility, the ice elastic properties are needed. Poisons ratio $(v)$ was assumed to be 0.295 and the ice density $(\rho)$ was assumed to be $910 \mathrm{~kg} / \mathrm{m}^{3}$ [27, 39-41]. Also, the volume of brine in the ice $\left(V_{b}\right)$ was assumed to be $20 \mathrm{ppt}$ which results in an elastic modulus $(E)$ of $2.98 \mathrm{GPa}$ from Equation 7 [27, 42, 43]. From these elastic properties, the flexural rigidity $(D)$ and the infinite plate mobility can then be determined (Equations 8, 9) [44]. It is seen in Figure 12 (a) that the theoretical infinite plate mobility is approximately $-66 \mathrm{~dB}$ (re $1 \mathrm{~m} / \mathrm{s} / \mathrm{N}$ ). This is very close to the FRF level between $20-500 \mathrm{~Hz}$ where there is little modal response in the ice, confirming that our measurement is valid.

$$
\begin{gathered}
E=10-0.351 V_{b} \\
D=\frac{E H^{3}}{12\left(1-v^{2}\right)} \\
\frac{\ddot{x}}{F_{\text {inf }}}=\frac{1}{8 \sqrt{D \rho H}}
\end{gathered}
$$


By comparison, the drive point FRF between the hammer and the hydrophone (Figure 12(b)) does not indicate that the hydrophone response is affected by the modal properties of the ice. This is clear because there are not any large peaks in the FRF.

The coherence for both the geophone and hydrophone are very close to one for the frequency ranges of interest $(10-2000 \mathrm{~Hz})$. This indicates that for this frequency range the input signal is linearly related to the output signal. Below $10 \mathrm{~Hz}$, there is little response from the ice for the given input signal, causing coherence to be low. Above approximately $1 \mathrm{kHz}$, the coherence also begins to drop off because the amount of energy input to the system (Figure 11) is decreasing.

During all experiments, the wind speed varied between roughly $3.9 \mathrm{~m} / \mathrm{s}$ to $22.8 \mathrm{~m} / \mathrm{s}$. The average wind speed was $15.0 \mathrm{~m} / \mathrm{s}$ (34 mph). This caused significant background noise at the microphone (despite using an environmental wind screen) that was not easily overcome by most of our sources (excluding the cannon). The in-air acoustic levels produced by the hammer hitting the ice was not loud enough to produce a coherent response at the microphone. Therefore, the drive point FRF between the hammer and the microphone are not reported.

\subsection{CANNON EXPERIMENT FRFs}

The input autopower spectra for the cannon source (Figure 13) was calculated by normalizing the microphone response at the source to $1 \mathrm{~m}$ distance. This was done assuming hemispherical spreading. It can be seen that there is input energy from the cannon between approximately $1 \mathrm{~Hz}-2 \mathrm{kHz}$.

The cannon FRFs were normalized to the cannon sound power. The cannon sound power $(W)$ was found with Equation 10 [34] assuming hemispherical spreading. The air density $\left(\rho_{0}\right)$ and speed of sound $(c)$ were approximated based on the average air temperature, -6.45 ${ }^{\circ} \mathrm{C}$, and standard pressure, $101.3 \mathrm{kPa}$, which was very close to the true pressure during our experiments. The autopower spectra of the receiver was then divided by the sound power of the source to compute the FRF.

$$
W=\frac{p^{2}}{\rho_{0} c} * 2 \pi r^{2}
$$

Looking at the drive point FRF between the cannon and the geophone in Figure 14(a), two large peaks are seen: one at $29 \mathrm{~Hz}$ and one at $800 \mathrm{~Hz}$. The $800 \mathrm{~Hz}$ peak corresponds with the mode seen in hammer drive point mobility. The $800 \mathrm{~Hz}$ peak is due to the throughthickness resonance - this time, excited by the cannon pressure wave. It is expected that the $29 \mathrm{~Hz}$ mode is due to a flexural wave in the ice layer. 


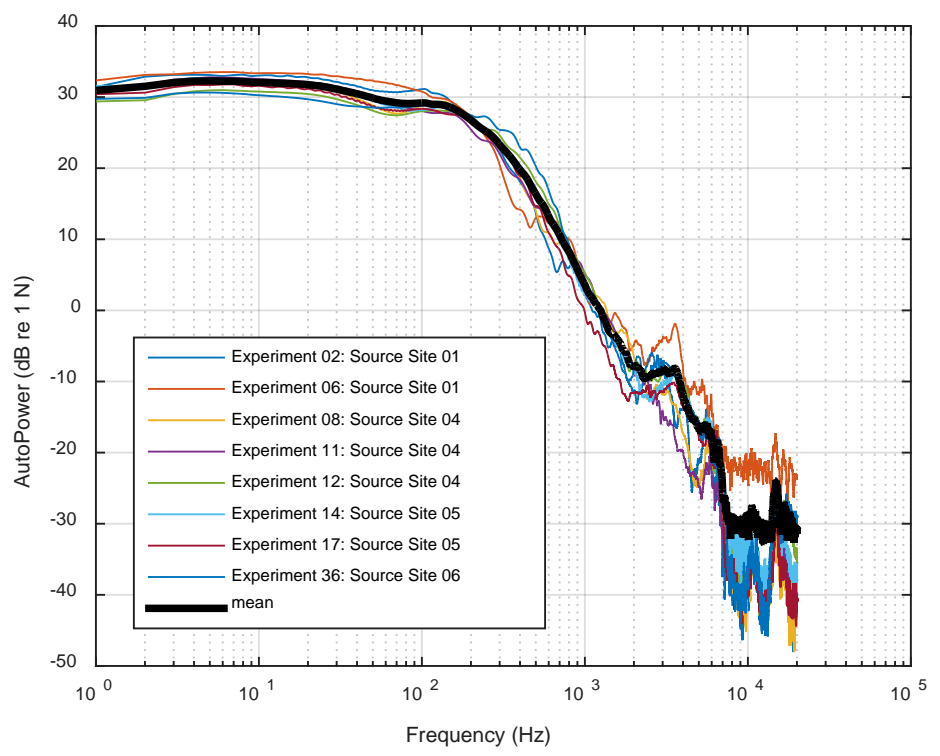

Figure 11. Hammer source input force spectra.

(a)

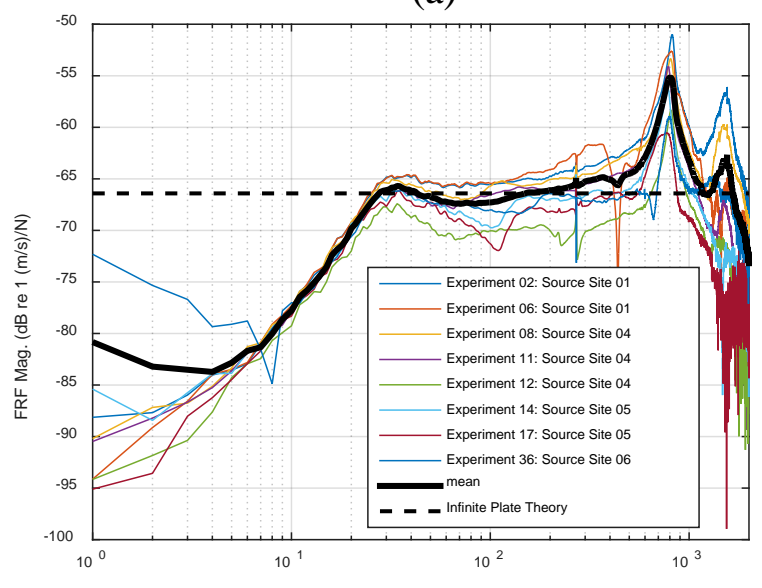

Frequency $(\mathrm{Hz})$

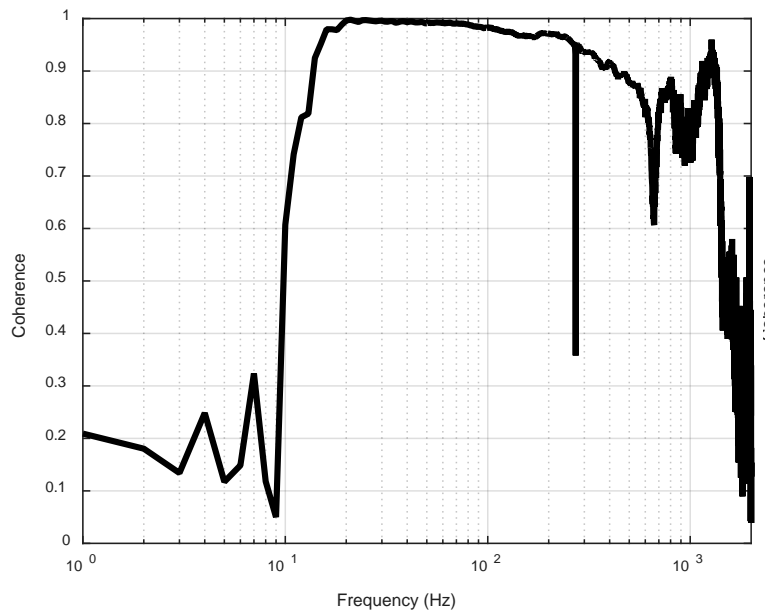

(b)

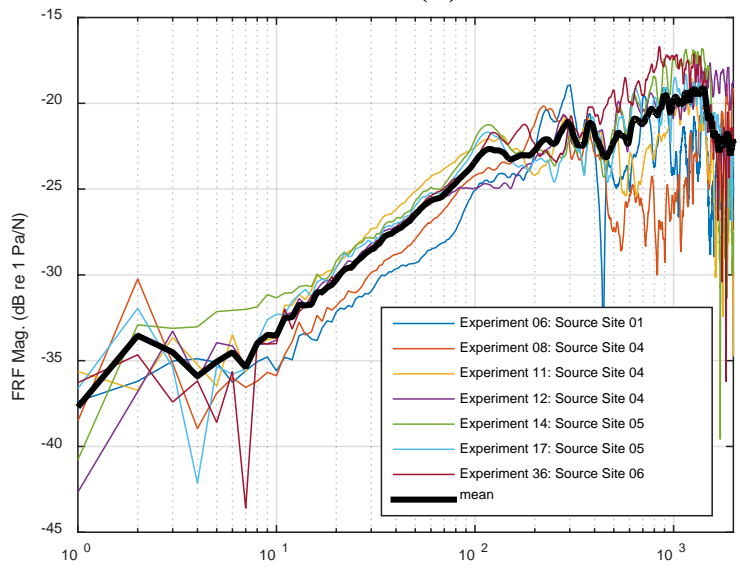

Frequency $(\mathrm{Hz})$

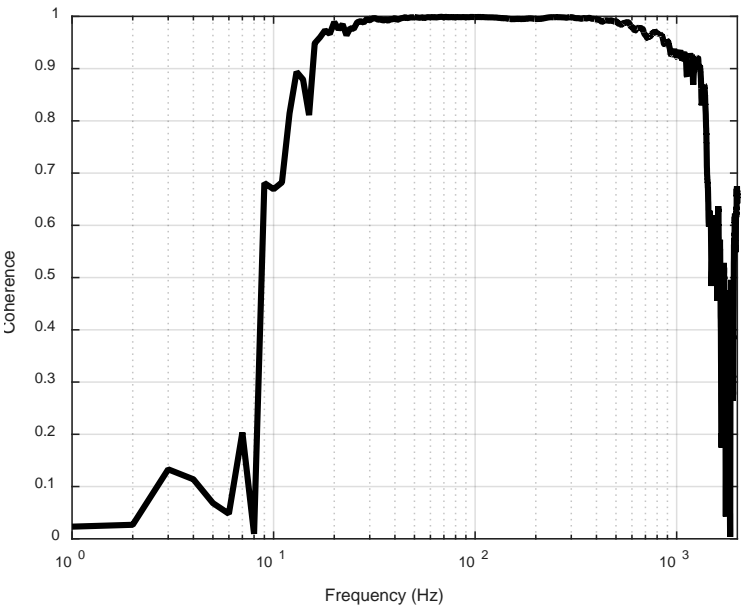

Figure 12. (a) Drive point FRF (mobility) and $\mathrm{COH}$ between the hammer source and z-direction geophone at the source location. Infinite plate mobility theory for sea ice (-66 dB) indicated by dashed line. (b) Drive point FRF and $\mathrm{COH}$ between the hammer source and the hydrophone at the source location. 


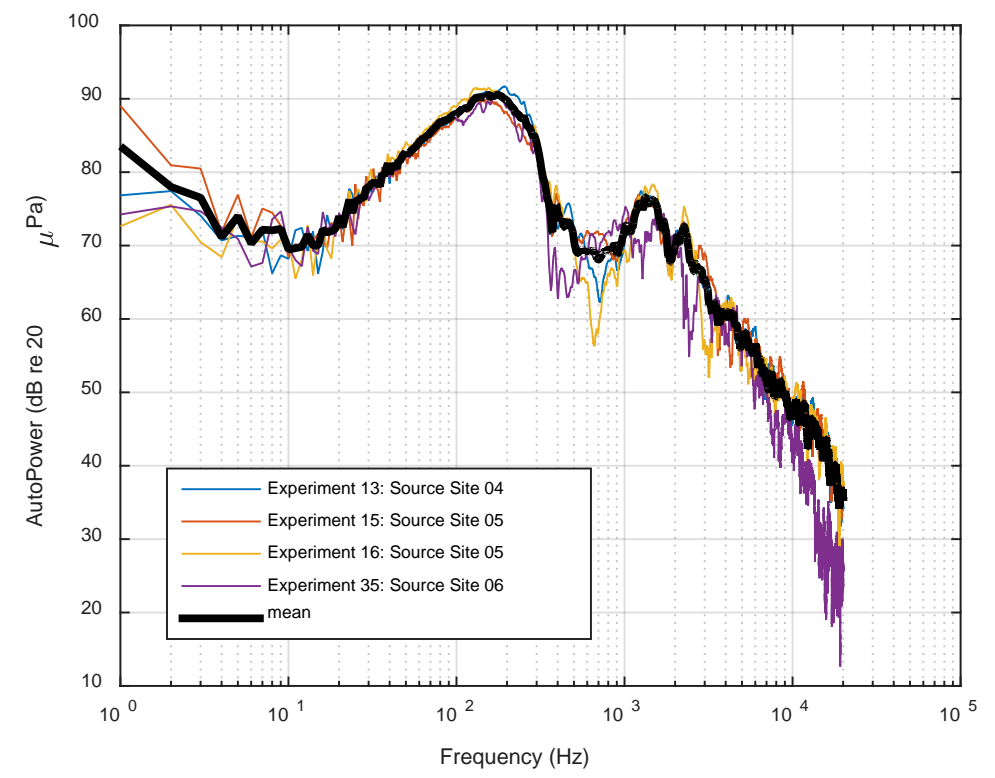

Figure 13. Cannon source input in-air sound pressure level (normalized to $1 \mathrm{~m}$ distance)

(a)
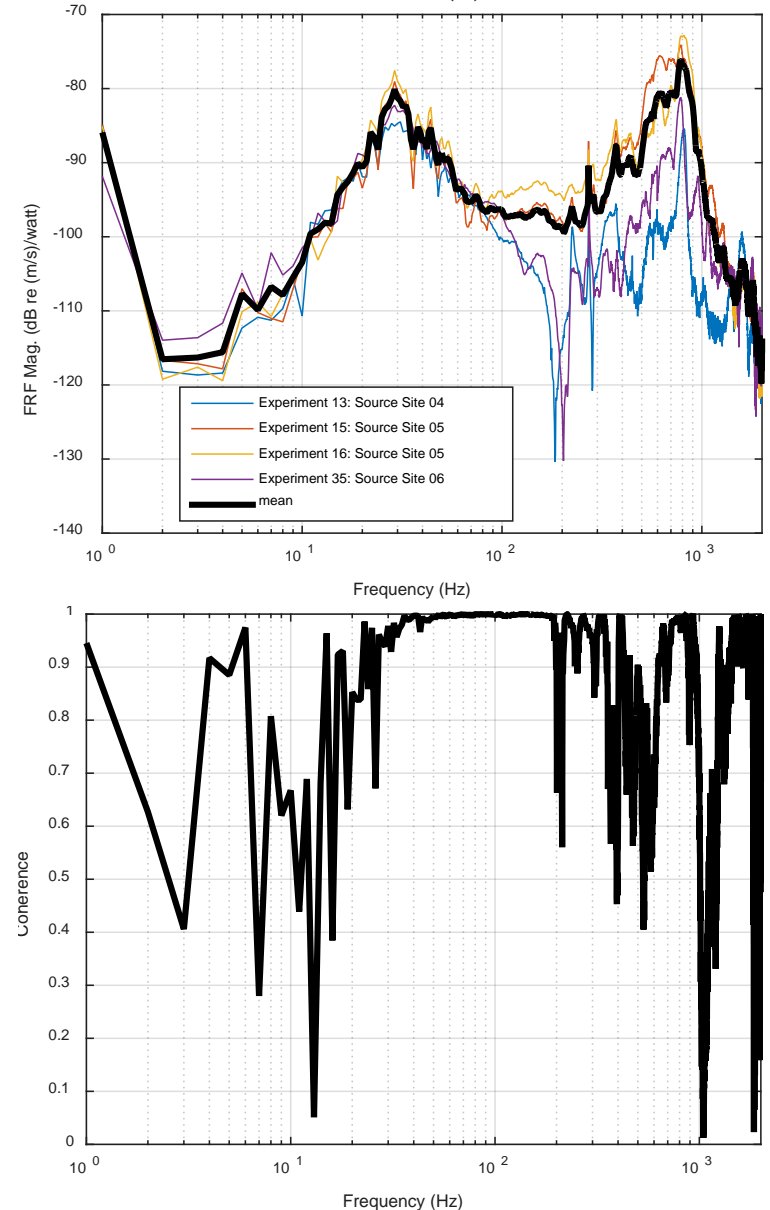

(b)
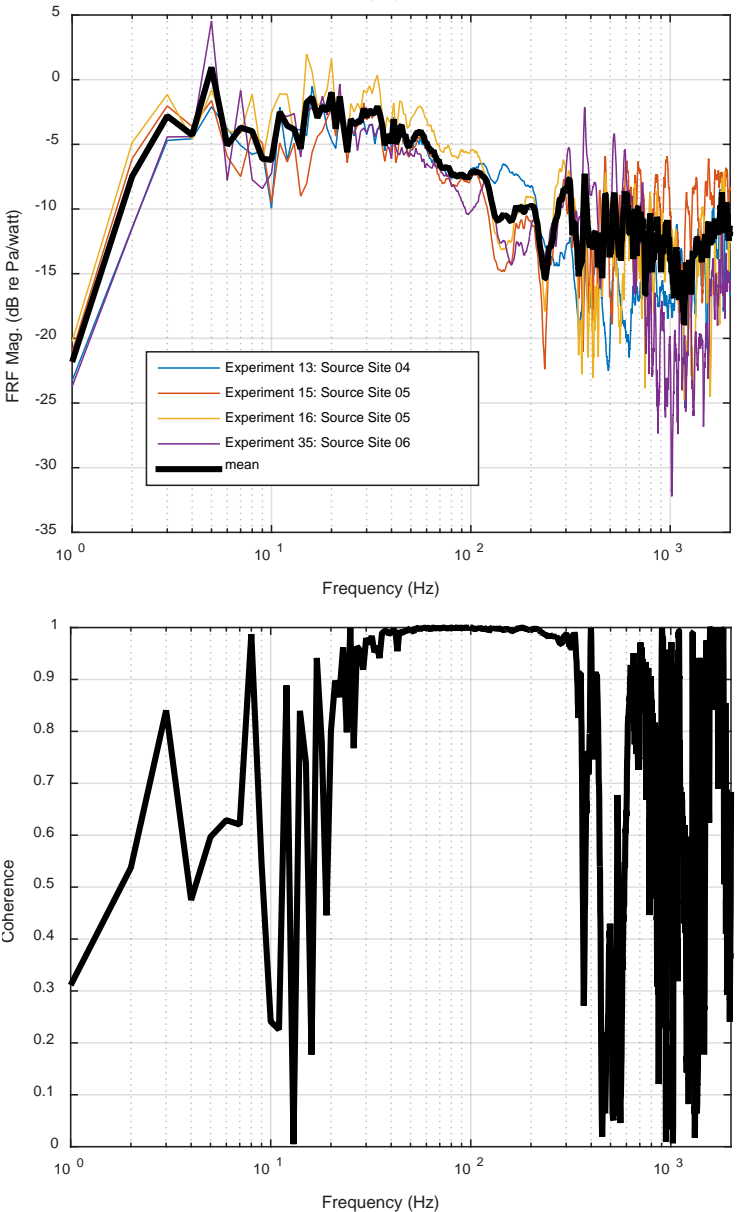

Figure 14. (a) Drive point FRF and $\mathrm{COH}$ between the cannon source and the z-direction geophone at the source site. (b) Drive point FRF and $\mathrm{COH}$ between the cannon source and the hydrophone at the source site. 
In particular it is expected that the $29 \mathrm{~Hz}$ mode is an air-coupled flexural wave. Since air-coupled flexural waves are non-dispersive, we would expect that the majority of its energy would appear at a single frequency. This is supported by Figure 14(a). To determine if this is in fact the air-coupled wave, we can look to research which has previously been done in this area $[3,8]$. The dimensionless parameter $\gamma$ relates the ice thickness $(H)$ to the speed of sound in air and to the air-coupled wave frequency.

$$
\gamma=\frac{H}{\lambda}=\frac{H f}{c}
$$

It has been shown [8] that $\gamma$ can also be expressed as a function of the compressional wave velocity in ice. Since we previously determined the compressional wave velocity in ice, we can determine a $\gamma$ value of approximately 0.092 from this function. From the enviromental conditions in Barrow during our testing, we know that the sound speed in air (c) was approximately $331 \mathrm{~m} / \mathrm{s}$. By rearranging Equation 11, we can determine that the air-coupled flexural wave frequency should be $29 \mathrm{~Hz}$ based on this information. This indicates that the observed $29 \mathrm{~Hz}$ peak is an air-coupled flexural wave in the ice.

In addition, looking at the time domain signal of the microphones and geophones in response to the cannon blast, we can directly see that there is an air-coupled gravity wave (Figure 15, 16). As predicted [3, 8], the flexural wave group velocity arrives before the pressure wave in air for an air-coupled gravity wave. Upon arrival of the in-air wavefront (i.e. when the speed of sound in air matches the phase velocity of the flexural wave), the flexual wave amplitude is immediately reduced and/or terminated.

When looking at Figure 14(b) the air-ice-water path seems to be behaving like a low-pass filter at the drivepoint location. This comes as no surprise when comparing to our evaluation of Figures 5-9. The modal properties of the ice, again, do not seem to have an effect on the hydrophone response.

At the source location, holes were drilled in the ice to deploy the hydrophones. Ideally, none of the acoustic energy from the cannon would pass through the hole in the ice to the hydrophone, however, this is almost certainly not the case. It is a point of question how much of the acoutic energy is passing through the hole in the ice because this will have some effect on out FRF measurement in Figure 14(b). Further investigation is needed to determine if this effect is significant.

The coherence in Figure 14 show that between roughly $20 \mathrm{~Hz}$ and $1000 \mathrm{~Hz}$ the system is relitively linear. At low frequencies, below $20 \mathrm{~Hz}$, coherence drops in both measurements. This is probably due to a combination of a lack of excitation energy at these frequecies lack of output from the system. At specific frequencies of interest (29 $\mathrm{Hz}$ and $800 \mathrm{~Hz}$ ) there are large increases in coherence indicating that the system is linear at these frequencies. Above $1000 \mathrm{~Hz}$, the coherence becomes much less than one. This is explained by lack of excitation energy. 

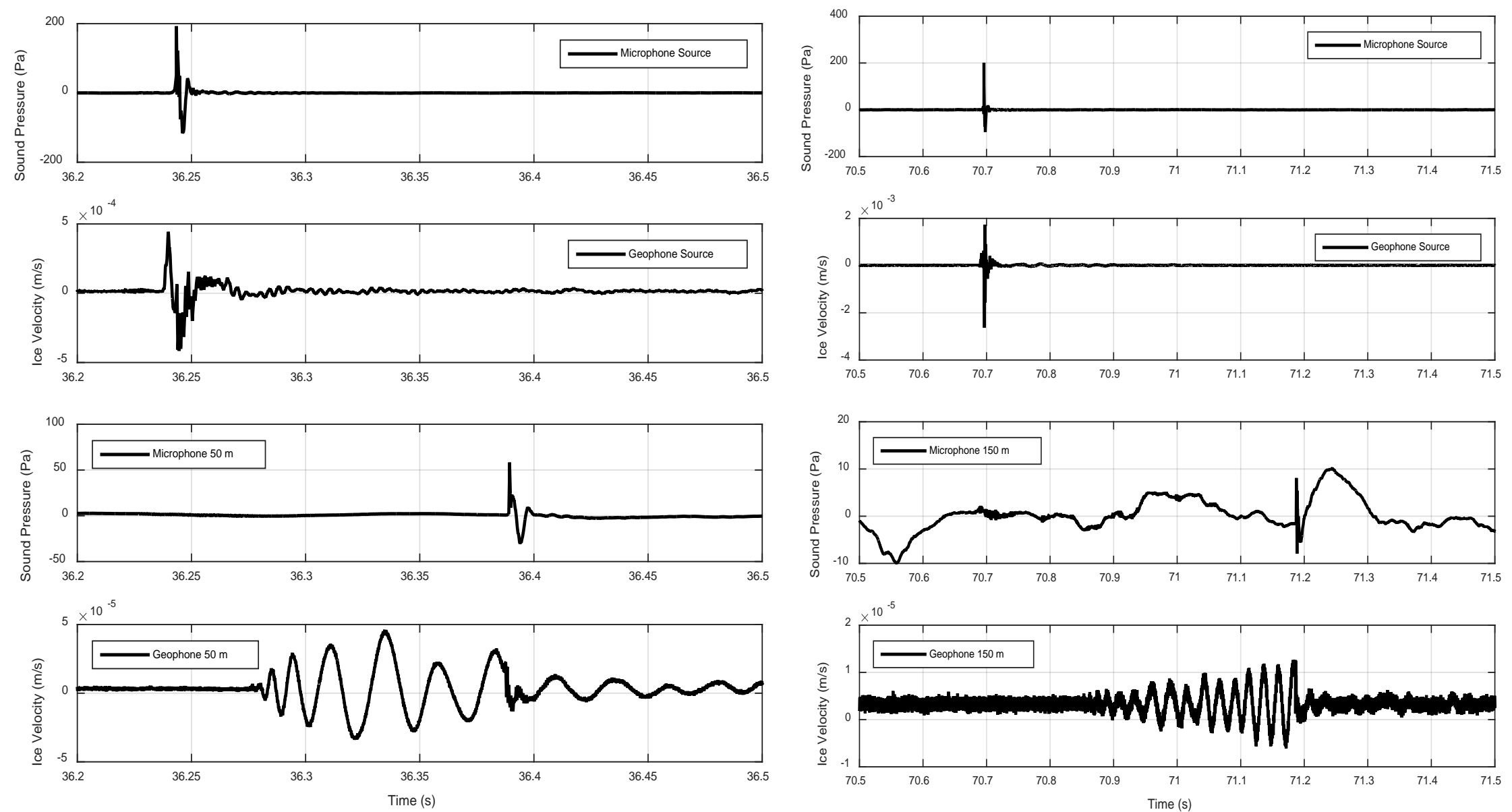

Figure 15. Air coupled gravity wave $(29 \mathrm{~Hz})$ visible at $50 \mathrm{~m}$ from the cannon source. Flexural wave amplitude in the ice is significantly

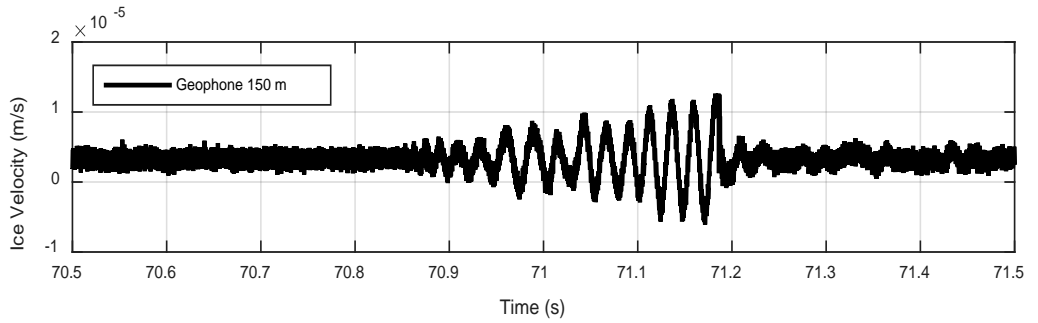

Figure 16. Air coupled gravity wave $(29 \mathrm{~Hz})$ visible at $150 \mathrm{~m}$ from the cannon source. Flexural wave amplitude in the ice is significantly reduced upon arrival of the in air wavefront. 


\section{TRANSMISSION LOSS AND ATTENUATION \\ 4.1 TONAL UNDERWATER TRANSMISSION LOSS}

To quantify the transmission loss for the underwater tones, the rms pressure of each tone was determined. For each tonal frequecy, the source and reveiver hydrophone data was time domain filtered with bandpass cuttoffs at plus/minus $5 \%$ of the center frequency. The rms pressure at the source and reveiver was then determined in the filtered band. The ratio of source rms pressure to receiver rms pressure was then calculated for each experiment in every frequency band. Figure 17 shows the rms pressure ratio as a function of distance. The data was then fit using linear regression to determine the transmission loss in each frequency band.

The attenuation of underwater sound (transmission loss) is reported in Table 3. The transmission loss is reported in terms of $\mathrm{dB}$ per doubling of distance. These values were taken from the fit curves in Figure 17. It can be seen that the values indicate that the acoustic spreading is somewhere between cylindrical (3 dB/doubling) and shperical (6 $\mathrm{dB} /$ doubling). Based on the $\mathrm{R}^{2}$ values in Table 3, the goodness of fit in the $400 \mathrm{~Hz}$ and $6400 \mathrm{~Hz}$ bands are low, but reasonable for the limited number of spatial samples available and the rough ice conditions at the test site.

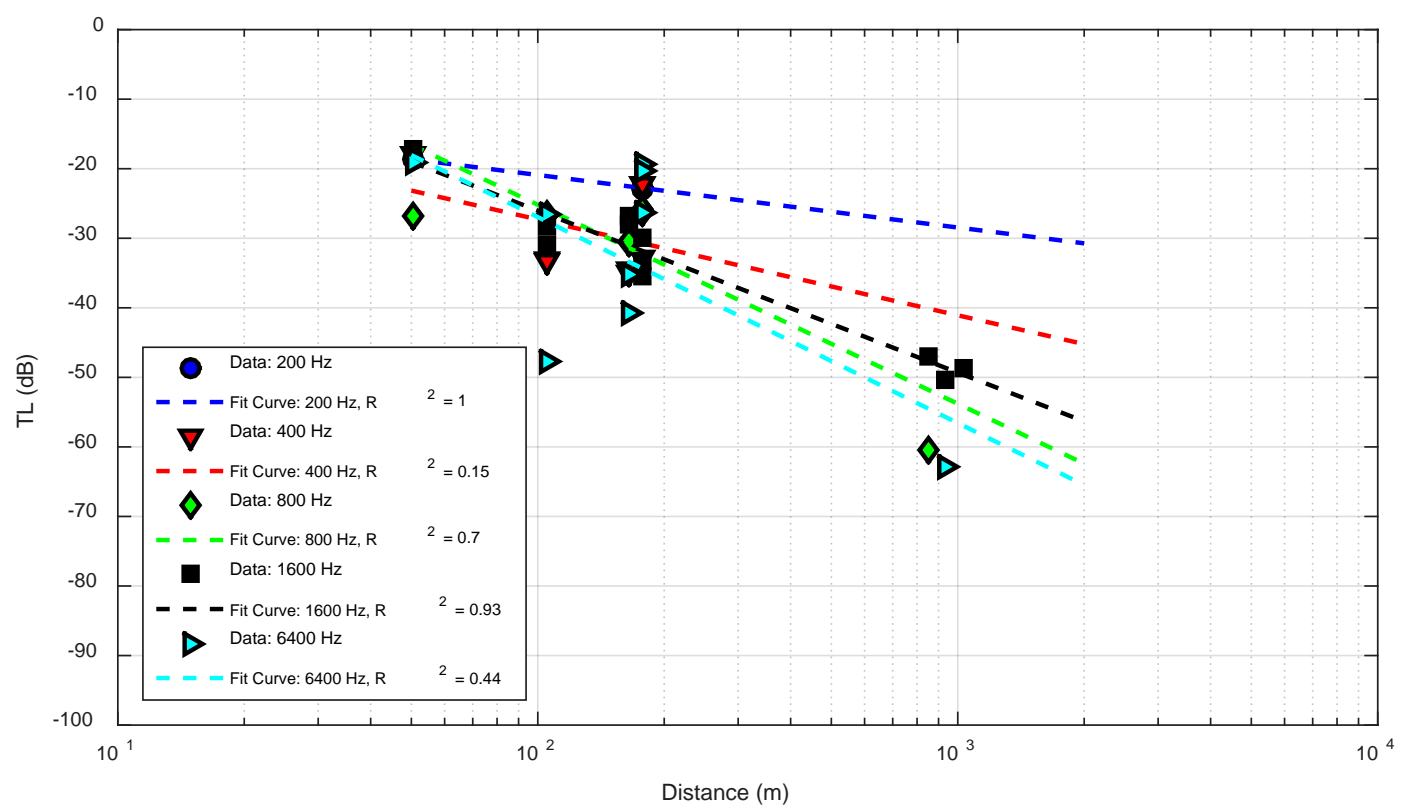

Figure 17. Under water acoustic transmission loss.

With the known transmission loss, the additional underwater attenuation could be calculated with Equation 12. The term $L_{p 2}-L_{p 1}$ represents the autopower ratio beteeen the source and receiver hydrophones, $r_{2}$ represents the distance between source and receiver where $r_{1}$ is normalized to $1 \mathrm{~m}$, and $\alpha$ represents the underwater absorption. The underwater absorption was determined to be approximately less than $0.3 \mathrm{~dB}$ at our longest range (1035 m) and highest frequency (6400 Hz in this case) of interest [45] and therefore 
was assumed negligible. Therefore, $\Delta L_{2}$ is the additional underwater attenuation shown in Figure 18. In general, additional attenuation increases as propagation distance increases due to absorption in the sea bed. At the $50 \mathrm{~m}$ location, the additional attenuation in the 800 $\mathrm{Hz}$ band is 7-10 dB greater than in other frequency bands. It is suspected, but not proven, that the increase in additional attenuation at $800 \mathrm{~Hz}$ could be due to the compressional, through-thickness mode of the ice at the same frequency.

$$
\Delta L_{2}=\left(L_{p 2}-L_{p 1}\right)+10 \log _{10}\left(\frac{r_{2}}{r_{1}}\right)+\alpha\left(r_{2}-r_{1}\right)
$$

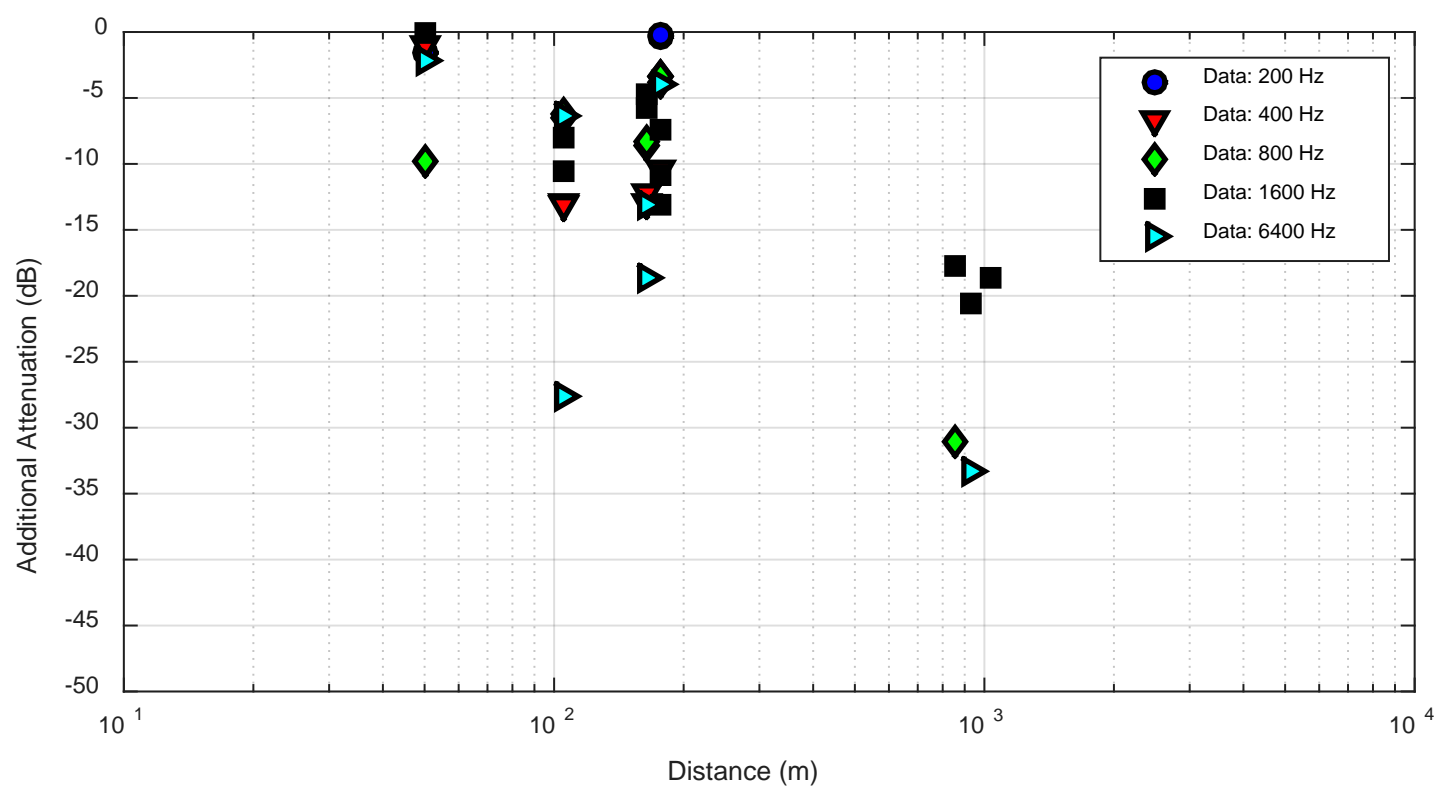

Figure 18. Underwater additional attenuation.

Table 3. Under water acoustic TL. Prediction from underwater tone fit curves.

\begin{tabular}{|c|c|c|}
\hline Frequency $(\mathrm{Hz})$ & $\begin{array}{c}\mathrm{dB} / \text { doubling of } \\
\text { distance }\end{array}$ & $\mathrm{R}^{2}$ \\
\hline 200 & 2.27 & 1.00 \\
\hline 400 & 4.15 & 0.15 \\
\hline 800 & 8.62 & 0.70 \\
\hline 1600 & 6.96 & 0.93 \\
\hline 6400 & 8.91 & 0.44 \\
\hline
\end{tabular}

\subsection{IN-AIR ATTENUATION}

To quantify the in-air attenuation, the ratio of autopowers between the cannon source and receiver microphones were calculated. The source microphone autopower spectra was normalized to $1 \mathrm{~m}$ distance from the source. The ratio of autopower spectra between the source and receiver were then filtered into octave bands which are indicated in Table 4 and Figure 19. For bands between $63-500 \mathrm{~Hz}$ the attenuation is roughly between cylindrical and spherical spreading ( $3 \mathrm{~dB}$ and $6 \mathrm{~dB}$ per doubling of distance respectively). These bands 
have $\mathrm{R}^{2}$ values which indicate a reliable fit of the data. Other bands have $\mathrm{R}^{2}$ values which are much less than one. Espcially 31.5 and $4000 \mathrm{~Hz}$ are questionable in their attenuation approximation. In these bands, more data is needed to approximate the attenuation.

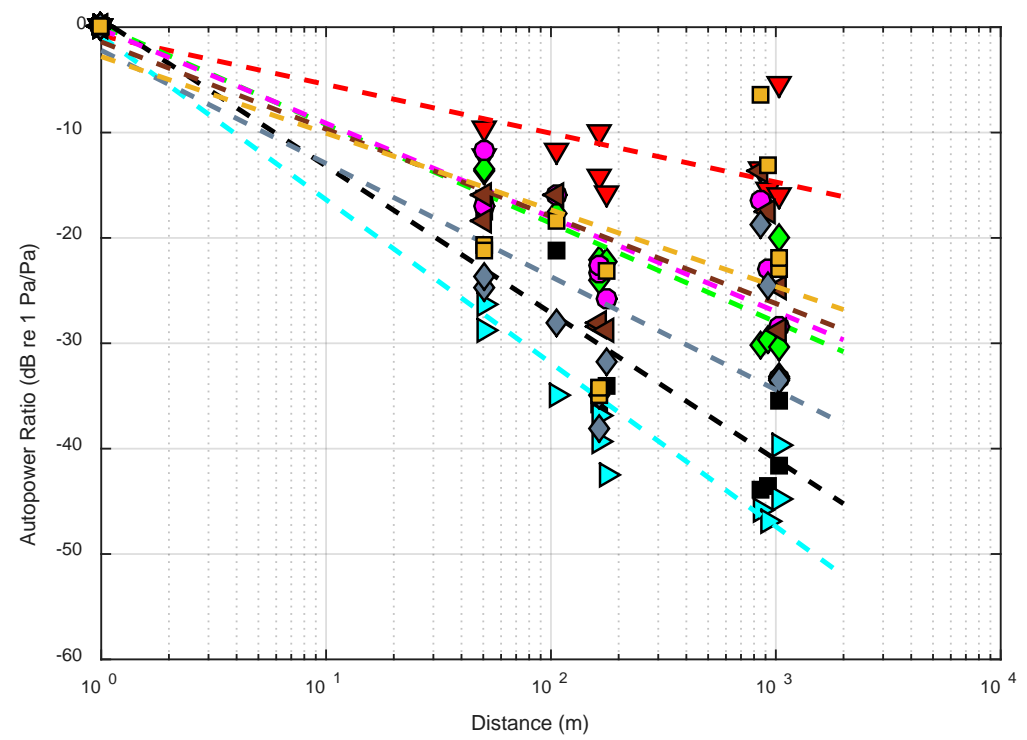

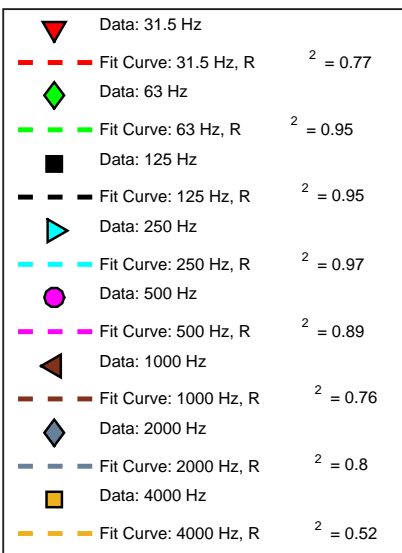

Figure 19. In air attenuation based on autopower spectra ratio between source microphone and receiver microphone.

Table 4. Attenuation in air. Prediction from autopower spectra ratio fit curves.

\begin{tabular}{|c|c|c|}
\hline Frequency $(\mathrm{Hz})$ & $\begin{array}{c}\mathrm{dB} / \text { doubling of } \\
\text { distance }\end{array}$ & $\mathrm{R}^{2}$ \\
\hline 31.5 & 1.0 & 0.66 \\
\hline 63 & 2.6 & 0.92 \\
\hline 125 & 4.1 & 0.93 \\
\hline 250 & 4.6 & 0.97 \\
\hline 500 & 2.4 & 0.85 \\
\hline 1000 & 2.2 & 0.71 \\
\hline 2000 & 3.0 & 0.77 \\
\hline 4000 & 1.9 & 0.44 \\
\hline
\end{tabular}

\subsection{AIR-ICE-WATER ATTENUATION}

Similar to the in-air attenuation, the attenuation between the cannon source and the hydrophones was calculated via an autpower spectra ratio. Again, the microphone autopower spectra was normalized to $1 \mathrm{~m}$. The ratio between source and receiver was then filtered into octave bands to determine the attenuation through the air, ice, and water (Table 5, Figure 20). The offset of the plot in Figure 20 represents the attenuation through the air and ice at the source location. Once the sound wave is in the water, the attenuation is consistent with cylindrical spreading ( $-3 \mathrm{~dB}$ per doubling of distance). This decay is evident in octave bands between $63-250 \mathrm{~Hz}$ (Table 5). In bands where the attenuation is less than $3 \mathrm{~dB}$ per doubling (i.e. 31.5, 500, 1000, $2000 \mathrm{~Hz}$ ), the $\mathrm{R}^{2}$ values are much less 
than one. This indicates that more data are needed to get an accurate approximation of the attenuation.

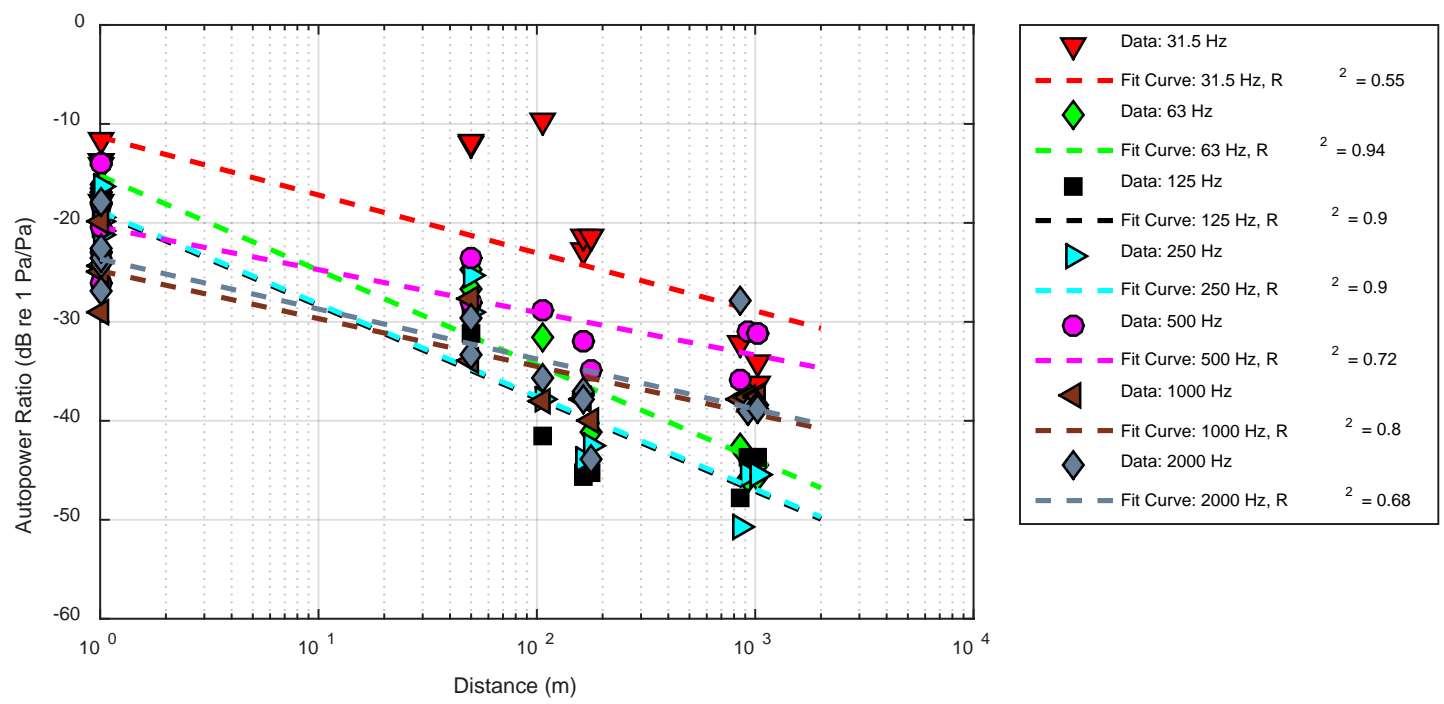

Figure 20. Attenuation through air-ice-water based on autopower spectra ratio between the source microphone and the receiver hydrophone.

Table 5. Attenuation through air-ice-water. Prediction from autopower spectra ratio fit curves.

\begin{tabular}{|c|c|c|c|}
\hline Frequency $(\mathrm{Hz})$ & $\begin{array}{c}\mathrm{dB} / \text { doubling of } \\
\text { distance }\end{array}$ & $\begin{array}{c}\text { Offset } \\
(\mathrm{dB})\end{array}$ & $\mathrm{R}^{2}$ \\
\hline 31.5 & 1.9 & -11.3 & 0.55 \\
\hline 63 & 3.1 & -15.2 & 0.94 \\
\hline 125 & 3.0 & -19.0 & 0.90 \\
\hline 250 & 3.0 & -18.8 & 0.90 \\
\hline 500 & 1.4 & -20.4 & 0.72 \\
\hline 1000 & 1.6 & -24.8 & 0.80 \\
\hline 2000 & 1.6 & -23.6 & 0.68 \\
\hline
\end{tabular}

\section{CONCLUSIONS}

Acoustic data was collected in Barrow, Alaska during April 2016 on a shore-fast ice sheet approximately 1.05 m thick. Frequency Response Functions were calculated between various sources and receivers. An air-coupled flexural wave and throughthickness compressional mode were identified in the FRFs and the compressional speed of sound was determined to be approximately $3360 \mathrm{~m} / \mathrm{s}$ in the ice. The attenuation was determined through the air, the ice, and the water. In frequency bands where there was sufficient data, the spreading of sound through the ice and water is close to $3 \mathrm{~dB}$ per doubling of distance. This is consistent with cylindrical acoustic spreading. In the air, the spreading varied more widely between 2.6-4.6 dB per doubling of distance, indicating something between cylindrical and spherical spreading. More data is needed to better characterize the spreading in this environment. 


\section{FUTURE WORK}

In preparation for completion of the degree of Doctor of Philosophy in Mechanical Engineering - Engineering Mechanics, the following initiatives will be completed by Miles Penhale, with the support of his advisor and committee. These initiatives will be prepared and carried out at Michigan Technological University and on Portage Lake, unless funding arises to perform experimentation in the arctic. If such funding becomes available, these initiatives may be adapted slightly, but without changing the main goals, to be carried out in the arctic environment.

- A method will be developed to track anthropogenic sources using intensity based methods in the air.

A main goal of this research is to develop a method for detecting, identifying, and tracking anthropogenic sources in the near-shore, thin ice environment. We will focus mainly on the tracking aspect of this initiative. One possible method for tracking is via multiple in-air intensity probes (pressure-pressure measurements). Each measurement of intensity gives an approximation of the direction to a sound source. By combining two or more intensity measurements, the source location can be estimated as a function of time.

- A method will be developed for characterizing arctic transmission loss, underwater, through the air, and (MAYBE) through the ice.

Transmission loss through the air, ice, and water was determined from our arctic data for the near-shore, thin ice environment. However, in many frequency bands, there was not enough data with sufficient signal-to-noise ratio to provide accurate fit curves. More data will be taken to quantify the transmission loss in these bands.

- The effects of ice bore holes on the Frequency Response Function between the air and the water will be investigated.

At all sites, there were holes drilled in the ice to deploy hydrophones. At source sites, an additional hole was also drilled to deploy the underwater sound source. It is unclear whether these holes had any significant contribution to the measured FRFs between the cannon and the hydrophone. An experiment will be designed to investigate this contribution.

- The impedance relationship at the boundary between the sea ice and the water will be analytically investigated. 
The assumption was made that the through-thickness mode in the ice layer is behaving like a quarter-wavelength resonator. This is a likely approximation because we expect the air-ice interface to behave like a pressure release and the ice-water interface to have high impedance. However, it is unclear exactly what the impedance relationship at the ice-water interface is because the boundary condition between the ice and the water is not a perfect reflecting surface. Therefore, this relationship needs to be quantified.

- Investigate if the ice thickness can be determined from the drive point mobility. (MAYBE)

For future applications of anthropogenic monitoring it would be beneficial to be able to determine the ice thickness with non-penetrative methods. One possible way to estimate ice thickness may be with the drive point frequency response function, especially with regards to a known force input to the ice.

- Investigate the $800 \mathrm{~Hz}$ additional attenuation with respect to the drive point through-thickness resonance. (MAYBE)

It was noted that the additional underwater attenuation was approximately 7-10 $\mathrm{dB}$ higher in the $800 \mathrm{~Hz}$ band at the drive point than other frequencies. There was also a through-thickness mode at $800 \mathrm{~Hz}$. It is possible that the additional attenuation in this band is higher because the ice resonance is removing energy from the water at this frequency. It is also possible that this is a complete coincidence or the data that we measured in the $800 \mathrm{~Hz}$ band is a statistical outlier. Because of the lack of data, we cannot make a distinction. To investigate this it would be necessary to quantify the bottom attenuation. 


\section{REFERENCES}

[1] M. Ewing and A. P. Crary, "Propagation of Elastic Waves in Ice. Part II," Journal of Applied Physics, vol. 5, pp. 181-184, 1934.

[2] M. Ewing, A. P. Crary, and A. M. Thorne, Jr., "Propagation of Elastic Waves in Ice. Part I," Journal of Applied Physics, vol. 5, pp. 165-168, 1934.

[3] F. Press and M. Ewing, "Theory of Air-Coupled Flexural Waves," Journal of Applied Physics, vol. 22, no. 892, 1951.

[4] M. Ewing, W. S. Jardetzky, and F. Press, Elastic Waves in Layered Media. McGraw-Hill, 1957.

[5] A. Langley, "The sound fields of an infinite, fluid-loaded plate excited by a point force," J. Acoust. Soc. Am., vol. 83, no. 4, 1987.

[6] T. C. Yang and T. W. Yates, "Flexural waves in a floating ice sheet: Modeling and Comparison with Data," J. Acoust. Soc. Am., vol. 97, no. 2, 1994.

[7] W. S. Jardetzky and F. Press, "Rayleigh Wave Coupling to Atmospheric Compression Waves," Seismological So. of Am., vol. 42, no. 2, pp. 135-144, 1952.

[8] F. Press, A. P. Crary, J. Oliver, and S. Katz, "Air-Coupled Flexural Waves In Floating Ice," American Geophysical Union, vol. 32, no. 2, 1951.

[9] F. Press and M. Ewing, "Propagation of Elastic Waves in a Floating Ice Sheet," American Geophysical Union, vol. 32, no. 5, 1951.

[10] A. R. Milne, "Shallow Water Under-Ice Acoustics in Barrow Strait," J. Acoust. Soc. Am., vol. 32, no. 8, 1960.

[11] K. Hunkins and K. Henry, "Shallow-Water Propagation in the Arctic Ocean," J. Acoust. Soc. Am., vol. 35, no. 542, 1963.

[12] A. R. Milne, "A 90 km Sound Transmission Test in the Arctic," J. Acoust. Soc. Am., vol. 35, no. 1459, 1963.

[13] T. C. Yang and G. R. Giellis, "Experimental characterization of elastic waves in a floating ice sheet,", J. Acoust. Soc. Am., vol. 95, no. 5, 1994.

[14] B. E. Miller and H. Schmidt, "Observation and Inversion of Seismo-Acoustic Waves in a Complex Artic Ice Enviroment," J. Acoust. Soc. Am., vol. 84, no. 4, 1990.

[15] R. W. Knapp, "Observations of the Air-Coupled Wave as a Function of Depth," Geophysics, vol. 51, no. 9, pp. 1853-1857, 1986.

[16] R. E. Sherrif, "Introduction to Seismic Methods," in Geophysical MethodsEnglewood Cliffs, NJ: Prentice Hall, 1989, pp. 209-227.

[17] W. I. Futterman, "Dispersive Body Waves," J. of Geophysical Research, vol. 67, no. 13, pp. 5279-5291, 1962.

[18] F. E. Francios and T. Wen, "Propagation of Sound Generated on the Ice Surface Into Water," in Oceans, Seattle, 1989.

[19] G. J. Heard, M. McDonald, N. R. Chapman, and L. Jaschke, " Underwater Lightbulb Implosions: A Useful Acoustic Source," in IEEE/Oceans, 1997.

[20] S. E. Dosso, G. J. Heard, and M. Vinnins, "Seismo-Acoustic Propagation in an Icecovered Arctic Ocean Environment," in MTS/IEEE Oceans Honolulu, 2001.

[21] J. Maslanik, J. Stroeve, C. Fowler, and W. Emery, "Distribution and Trends in Arctic Sea Ice Age Through Spring 2011," Geophysical Research Letters, vol. 38, 2011.

[22] J. C. Stroeve, T. Markus, L. Boisvert, J. Miller, and A. Barrett, "Changes in Arctic Melt Season and Implications for Sea Ice Loss," Geophysical Research Letters, vol. 41, pp. 1216-1225, 2014.

[23] J. Rodrigues, "The Rapid Decline of the Sea Ice in the Russian Arctic," Cold Regions in Sci. and Technology, vol. 54, pp. 124-142, 2008. 
[24] R. Lei, H. Xie, J. Wang, M. Lepparanta, I. Jonsdottir, and Z. Zhang, "Changes in Sea Ice Conditions along the Arctic Northeast Passage from 1979-2012," Cold Regions in Sci. and Technology, vol. 119, pp. 132-144, 2015.

[25] F. Lasserre and S. Pelletier, "Polar Super Seways? Maritime Transport in the Arctic: an Analysis of Shipowners' Intentions," J. of Transport Geography, vol. 19, pp. 1465-1473, 2001.

[26] M. Roston, "The Northwest Passage's Emergence as an International Highway," Southwestern J. of International Law, vol. 15, 2009.

[27] G. W. Timco and W. F. Weeks, "A Review of the Engineering Properties of Sea Ice," Cold Regions in Sci. and Technology, vol. 60, 2010.

[28] S. Somanathan, P. C. Flynn, and J. Szymanski, "The Northwest Passage: A Simulation," in Winter Simulation Confrence, 2006.

[29] L. C. Smith and S. R. Stephenson, "New Trans-Arctic Shipping Routes Navigable by Midcentury," Proc. of the Nat. Academy of Sci. of the United States of America, vol. 110, no. 13, pp. 1191-1195, 2013.

[30] S. R. Stephenson, L. W. Brigham, and L. C. Smith, "Marine Accessibility Along Russia's Northern Sea Route," Polar Geography, vol. 37, no. 2, pp. 111-133, 2014.

[31] D. L. Brown and R. J. Allemang, "Review of Spatial Domain Modal Parameter Estimation Procedures and Testing Methods," in IMAC 2009.

[32] W. Heylen, S. Lammens, and P. Sas, Modal Analysis Theory and Testing. K.U. Leuven, 2013.

[33] C. V. Karsen. (1984) Averaging for Improved Frequency Response Functions. S.V. Sound and Vibration. 18-24.

[34] H. W. Lord, W. S. Gatley, and H. A. Evensen, Noise Control for Engineers. Malabar, CA.: Krieger Publishing Company, 1980.

[35] "CastAway User Manual - CTD Principles of Operation," ed, 2010, p. 74.

[36] N. P. Fofonoff and R. C. Millard, "Algorithims for computation of fundamental properties of seawater," Unesco technical papers in marine science, no. 44, 1983.

[37] J. S. Bendat and A. G. Piersol, Random Data: Analysis and Measurement Procedures, 3 ed. Wiley, 2000.

[38] L. E. Kinsler, A. R. Frey, A. B. Coppens, and J. V. Sanders, Fundamentals of Acoustics. Wiley, 1999.

[39] G. W. Timco and R. M. W. Frederking, "A Review of Sea Ice Density," Cold Regions in Sci. and Technology, vol. 24, 1995.

[40] N. K. Sinha, "Effective Poisson's Ratio of Isotropic Ice," in International Offshore Mechanics and Arctic Engineering Symposium, Huston, TX, 1987, vol. IV, pp. 189-195.

[41] J. R. Murat and L. M. Lainey, "Some Experimental Observations on the Poisson's Ratio of Sea Ice," Cold Regions in Science and Technology, vol. 6, pp. 105-113, 1982.

[42] M. P. Langleben, "Young’s Modulus for Sea Ice,," Canadian J. of Physics, vol. 40, no. 1, 1962.

[43] A. Traetteberg, L. W. Gold, and R. Frederking, "The Strain Rate and Temperature Dependence of Young's Modulus of Ice," in IAHR International Symposium on ICE Problems, Hanover, New Hampshire, 1975, vol. 3.

[44] S. A. Hambric, S. H. Sung, and D. J. Nefske, Engineering Vibroacoustic Analysis: Methods and Applications, 1 ed. Wiley, 2016.

[45] R. J. Urick, "Propagation of Sound in the Sea: Transmission Loss, I and II," in Principles of Underwater Sound3 ed.: Peninsula Publishing, 1996. 